\title{
Review Article \\ Diagnosis and Treatment of Neurological and Ischemic Disorders Employing Carbon Nanotube Technology
}

\author{
Patrick P. Komane, ${ }^{1,2}$ Yahya E. Choonara, ${ }^{1}$ Lisa C. du Toit, ${ }^{1}$ Pradeep Kumar, \\ Pierre P. D. Kondiah, ${ }^{1}$ Girish Modi, ${ }^{3}$ and Viness Pillay ${ }^{1}$ \\ ${ }^{1}$ Wits Advanced Drug Delivery Platform Research Unit, Department of Pharmacy and Pharmacology, School of Therapeutic Sciences, \\ Faculty of Health Sciences, University of the Witwatersrand, Johannesburg, 7 York Road, Parktown 2193, South Africa \\ ${ }^{2}$ Department of Applied Chemistry, University of Johannesburg, P.O. Box 17011, Doornfontein, Johannesburg 2028, South Africa \\ ${ }^{3}$ Department of Neurology, Division of Neurosciences, Faculty of Health Sciences, University of the Witwatersrand, \\ Johannesburg, 7 York Road, Parktown 2193, South Africa
}

Correspondence should be addressed to Viness Pillay; viness.pillay@wits.ac.za

Received 7 June 2016; Revised 19 September 2016; Accepted 28 September 2016

Academic Editor: Taslim A. Al-Hilal

Copyright ( 2016 Patrick P. Komane et al. This is an open access article distributed under the Creative Commons Attribution License, which permits unrestricted use, distribution, and reproduction in any medium, provided the original work is properly cited.

\begin{abstract}
Extensive research on carbon nanotubes has been conducted due to their excellent physicochemical properties. Based on their outstanding physicochemical properties, carbon nanotubes have the potential to be employed as theranostic tools for neurological pathologies such as Alzheimer's disease and Parkinson's disease including ischemic stroke diagnosis and treatment. Stroke is currently regarded as the third root cause of death and the leading source of immobility around the globe. The development and improvement of efficient and effective procedures for central nervous system disease diagnosis and treatment is necessitated. The main aim of this review is to discuss the application of nanotechnology, specifically carbon nanotubes, to the diagnosis and treatment of neurological disorders with an emphasis on ischemic stroke. Areas covered include the conventional current diagnosis and treatment of neurological disorders, as well as a critical review of the application of carbon nanotubes in the diagnosis and treatment of ischemic stroke, covering areas such as functionalization of carbon nanotubes and carbon nanotubebased biosensors. A broad perspective on carbon nanotube stimuli-responsiveness, carbon nanotube toxicity, and commercially available carbon nanotubes is provided. Potential future studies employing carbon nanotubes have been discussed, evaluating their extent of advancement in the diagnosis and treatment of neurological and ischemic disorders.
\end{abstract}

\section{Introduction}

Neurological and ischemic disorders incorporate a variety of sporadic and hereditary conditions. They are characterized by the progressive loss of structure and function of neurons often associated with neuronal death. The causes of neurological and ischemic diseases are very complex and are linked to a variety of factors such as aging, lifestyle, environmental factors, and heredity [1-3].

Alzheimer's disease (AD) and Parkinson's disease (PD) are the most common neurodegenerative diseases. An estimated 24 million people around the globe suffer from dementia and $\mathrm{AD}$ comprises $60 \%$ of this number. $\mathrm{AD}$ is characterized pathologically by cerebral atrophy and clinically by memory and learning impairment [2]. According to the Alzheimer's Association, 13\% of people over 65 suffer from $\mathrm{AD}$ in developed countries. It is the fifth leading cause of death in patients at this age [4]. The cause of $\mathrm{AD}$ is unknown and current treatments are symptomatic. Current treatments for cognitive impairment in $\mathrm{AD}$ are based on neurotransmitter or enzyme replacement. These provide a wide spectrum of symptomatic benefits and include acetylcholinesterase inhibitors, antioxidants, amyloid-targeted drugs, and nerve growth factors. It seems that none of the available therapies are able to cure $\mathrm{AD}$ or to attenuate its progression. Nanotechnology may provide a possible solution to overcome many obstacles for the treatment of $\mathrm{AD}$ by affording targeted drug 
delivery and enhancing the bioavailability and efficacy of various drugs and other bioactive agents [5].

Parkinson's disease (PD) is a central nervous system disease with difficulties in body movements. Typical symptoms include tremor, rigidity and bradykinesia, unstable posture, and difficulty in walking [6]. PD is the second most common neurodegenerative disorder after Alzheimer's disease. It affects more than 5 million people globally and approximately a million people in the USA. The hallmark features of PD pathology include progressive loss of dopaminergic neurons leading to significant loss of the dopaminergic levels. Dopamine (DA) is the neurotransmitter responsible for transmitting the electrical signals required for normal physical motion. This deficit is treated by restoration of dopaminergic activity by levodopa (precursor of dopamine) and dopamine receptor antagonist. Currently, frontline therapy for PD is the oral administration of dopamine agonists such as levodopa. Patients become less responsive to levodopa as the disease progresses and begin to develop motor side effects. Adverse effects include constipation, urinary retention, glaucoma, and cognitive impairment [7]. PD remains incurable to date. The current pharmacological and nonpharmacological treatments are able to offer only symptomatic relief for patients. Available therapies aim to improve the functional capacity of the patient for as long as possible; however they do not modify the progression of the neurodegenerative disorder [6]. The advent of nanotechnology may provide a solution to overcome the diagnostic and neurotherapeutic challenges of this disease.

Ischemic disorders include ischemic stroke which can be defined as a rapid onset of a persistent neurologic deficit. It is a cerebrovascular disorder whereby the brain is deprived of oxygen, nutrients, and glucose as a result of obstruction of the vessels supplying the brain $[8,9]$. Symptoms are usually sudden, within seconds to hours, and can include unilateral weakness or numbness of the face, arms, or legs, aphasia, visual impairment, dysarthria, confusion, loss of balance and coordination, difficulty with walking, and, in severe cases, even death. Stroke is considered as the fourth highest cause of death in the United States. It is the third major cause of death in developed countries and the second root cause of death around the world [10]. Of all stroke cases, ischemic stroke contributes to $80-87 \%$ of all the stroke cases, with the remainder being hemorrhagic stroke. Current treatments of ischemic stroke with tissue plasminogen activator (tPA) have various drawbacks such as short window period, nonspecificity, cell death, cerebral oedema, and damage to blood brain barrier (BBB) [11]. Nanotechnology has been widely considered as a promising tool for theranosis of neurodegenerative diseases including ischemic disorders [10].

The main challenge of the successful diagnosis and treatment of the neurological and ischemic disorders is the central nervous system (CNS) access. The delivery of drugs and imaging agents to the nervous system is mainly limited by the presence of two anatomical and biochemical dynamic barriers: the blood brain barrier (BBB) and bloodcerebrospinal fluid barrier (BCSFB). These barriers tightly seal the central nervous system (CNS) from the changeable milieu of blood. There is a need to design novel therapeutic systems to target the CNS in an effective and efficient manner for successful diagnosis and treatment of neurological and ischemic disorders.

Advances in nanomedicine are expected to have a major impact in neurological research. These will significantly contribute to our further understanding of the CNS and the development of novel therapeutic approaches for neurological intervention $[3,5]$. The use of carbon nanotubes (CNTs) is one of the most attractive strategies for neurological applications. They are synthesized by using the most common technique, namely, chemical vapour deposition (CVD), as illustrated in Figure 1. CNTs can be synthesized and functionalized for the intended purpose. They have shown evidence of their electrical conductive capacity, strong mechanical properties, and morphological similarity to neurites [12]. Therefore, the emergence of nanotechnology provides hope that it will revolutionize diagnosis and treatment of CNS disorders.

This paper discusses the application of carbon nanotubes in neurological and ischemic disorders. In this paper, the uses of carbon nanotubes in diagnosis and treatment of neurological pathologies and ischemic disorders are discussed in detail with more emphasis on ischemic stroke. Areas covered include the conventional current diagnosis and treatment of neurological disorders, as well as a critical review of the application of carbon nanotubes in the diagnosis and treatment of ischemic stroke, covering areas such as functionalization of carbon nanotubes and carbon nanotube-based biosensors. A broad perspective on carbon nanotube stimuliresponsiveness, carbon nanotube toxicity, and commercially available carbon nanotubes is provided. Potential future studies employing carbon nanotubes have been discussed, evaluating their extent of advancement in the diagnosis and treatment of neurological and ischemic disorders.

\section{Current Diagnosis and Treatment of Ischemic Stroke}

Radiation and chemotherapy are the current therapies for stroke; however they produce notable adverse effects. They are painful and inefficient and cause death to healthy cells and tissues in addition to the diseased. The most commonly used tools for diagnosis of stroke are computed tomography and magnetic resonance imaging. Their use is very limited as a result of cost, unavailability, and radiation exposure from these instruments. Acute therapy, which involves the dissolution of blood clots, is currently preferred over radiation and chemotherapy for ischemic stroke treatment [16].

Glucocorticoids such as methylprednisolone and dexamethasone are utilized in ischemic stroke therapy. Glucocorticosteroids possess anti-inflammatory properties rendering them potentially effective in the treatment of ischemic stroke. Glucocorticoids have been proven effective in the treatment of cerebral edema and cerebrovascular disease inflammation since they are able to cross blood brain barrier (BBB) [17]. However, the therapeutic potential of glucocorticoids is negatively affected by the short circulatory half-lives and poor pharmacokinetics. Administration of extremely high concentrations of glucocorticoids is required in order for the 


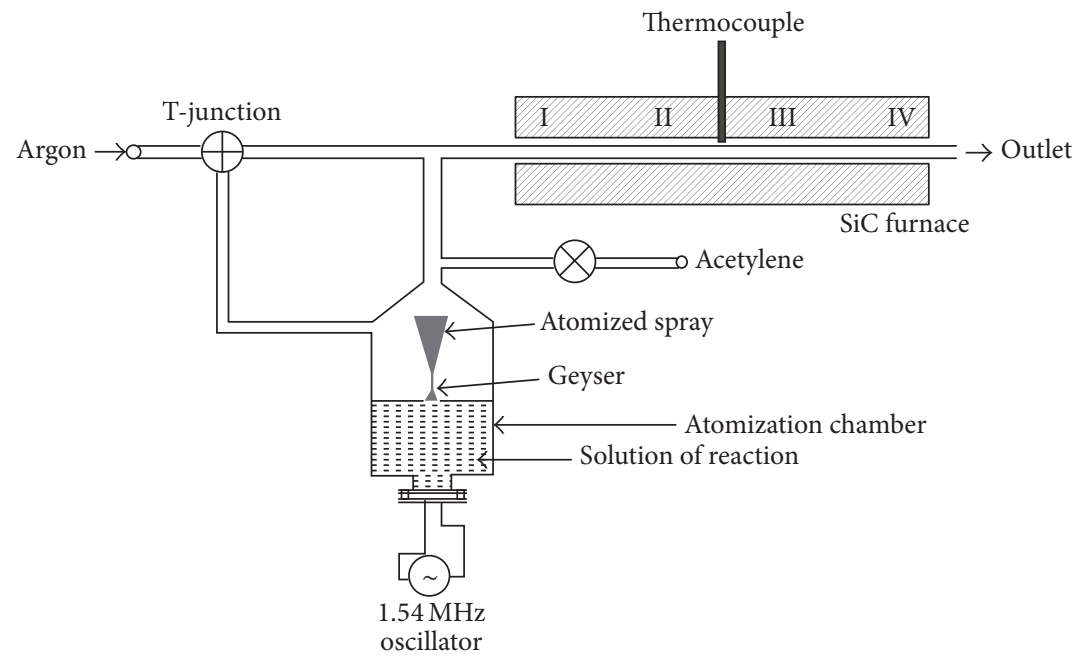

FIGURE 1: Schematic representation of a chemical vapour deposition tube furnace with a nebulizer. A catalyst reacts with a precursor in the atomization chamber and the reactants are then carried into the high temperature furnace by argon gas. Nucleation sites are formed by the nanoparticles from the catalyst for the growth of carbon nanotubes from the carbon source acetylene. The evolved gases from the reaction are wiped out of the furnace by argon gas via the outlet. Adapted from Nunes and coworkers [13] with a permission from Elsevier.

glucocorticoids to be effective and this could result in serious systemic side effects [18].

In addition, stenting is also used for treatment of ischemic stroke but it has many disadvantages such as lysis of the thrombus which circulates to adjacent arteries, invasiveness as it requires surgery of the vessels, and possible damage to vessels during surgery and the need of antiplatelet therapy during this procedure [19].

Based on the current challenges, there is an urgent need for proper diagnosis and effective and efficient treatment of neurological diseases including ischemic stroke.

\section{Carbon Nanotubes in the Diagnosis and Treatment of Central Nervous System Disorders}

Nanomedicine is an emerging field where engineered nanomaterials are utilized for the detection, treatment, and prevention of certain diseases including neurological disorders. Despite impressive research that is adding value to the body of knowledge in the field of nanomedicine at an alarming rate, this field is currently at its embryonic stage $[2,3]$.

Carbon nanotubes (CNTs) are a new group of nanomaterials that has demonstrated promising outcomes for the advancement in technology in the field of medicine [4-6]. They have a variety of properties making them useful tools in neurobiological applications. Iijima discovered CNTs in 1991 [20]. CNTs are electrically and thermally conductive and have ultralight weight. They are highly flexible, very strong, and inert but can undergo chemical modification with various functional groups depending on their intended use [8-10]. CNTs structural backbone consists of carbon atoms which exhibit thermal and electronic conductivity including great strength.
CNTs are synthesized by various methods; the widely used approaches are chemical vapour deposition (CVD), laser ablation, and arc discharge $[11,12]$. CVD is the most suitable and preferred method of CNT synthesis (as illustrated in Figure 1) for mass production due to low deposition, low cost, and scalability [21]. CNTs in their native state do not dissolve in most aqueous solvents, with this property rendering their application in nanomedicine extremely difficult. CNTs need to be functionalized to enhance their distribution in aqueous solvents and to improve their biocompatibility for application in physiological conditions including the central nervous system (CNS) $[10,17,18]$.

The delivery of drugs to the nervous system is mainly limited by the presence of two anatomical and biochemical dynamic barriers: the blood brain barrier (BBB) and bloodcerebrospinal fluid barrier (BCSFB) separating the blood from the cerebral parenchyma [1]. These barriers tightly seal the central nervous system (CNS) from the changeable milieu of blood. The presence of these barriers restricts drug delivery to the CNS leading to inefficient and ineffective diagnosis and therapy of neurological disorders $[22,23]$. There is a promise that nanotechnology will revolutionize neurological disease diagnosis and treatment [3].

Feynman recognized the potential of engineering atoms and molecules at the nanometer range in 1959. He suggested that materials at this nanometer level are in possession of distinctive physical properties which could be of great benefit to humankind [24]. Nanotechnology involves the development and application of materials at nanometer level with very distinctive functional properties lacking in huge materials. Nanomaterials can interact with physiological systems at the molecular and supramolecular level. They can be redesigned to respond to particular cell milieu and trigger desired biological activities in cells and tissues while reducing adverse effects [3]. 
Notwithstanding the promising research outcomes, in vivo implementation of nanotechnological procedures and CNT platforms particularly for neuroregeneration is only at an early stage with only a limited number of pilot studies performed to date. CNTs have been utilized in vivo with great success in bone implants and as drug delivery vehicles for the treatment of rheumatoid arthritis and osteoporosis in bone diseases and cancer in various body organs [9, 21, 25-29]. Very few preclinical studies for the successful in vivo usage of CNTs in neuroregeneration and neuroprotection have been performed [30].

CNTs have shown evidence of their electrical conductive capacity, strong mechanical properties, and morphological similarity to neurites [12]. Based on their unique properties, CNTs seem to be promising in diagnosis and treatment of neurological and ischemic diseases.

\section{Carbon Nanotubes Potential Toxicity in Living Cells including Neural Tissue}

Clinical trials of CNTs for diagnostic and therapeutic applications can only be initiated when a clear picture about their toxicity in the biological environment has been obtained [31]. CNT toxicity in living cells is currently a controversial issue. CNTs have different effects in different cells, tissues, and organs, being biologically benign in some cells and hazardous in other cell types [32]. Efficacy and side effects of CNTs are highly dependant on a variety of parameters including dose and route of administration of CNTs, type of exposure, and length and diameter of CNTs as illustrated in Table 1.

There is a need for research for determination of the penetration mechanism of CNTs into cells, tracking of location of CNTs once internalized, and identification of relevant cytotoxic mechanisms. Furthermore, research needs to be executed to relook the nanotoxicity effect as a result of physicochemical parameters, which include impurities, length and diameter, surface functionalization, and wettability of CNTs. CNTs use three common routes to gain access into the body, namely, ingestion, absorption through the skin, and inhalation [33]. Other routes of administration include intratracheal administration, abdominal implantation, and intravenous injection with subsequent investigation of their nanotoxicity [34].

Functionalized CNTs are internalized into the cells via two most widely accepted mechanisms, namely, active endocytosis and passive nanopenetration. Cells undergo oxidative stress following CNT internalization as a result of induction of oxidants and toxic enzymes. Oxidative stress generates free radicals and reactive oxygen species (ROS). Excessive free radicals stimulate lipid peroxidation, protein degradation, and oxidative damage to DNA. ROS may lead to harmful effects in cells such as apoptosis, DNA damage, amino acid oxidation, and inhibition of enzymes [35]. Proinflammatory cytokines and apoptosis are regulated by protein kinase and nuclear factor kappa $\mathrm{B}(\mathrm{NF}-\kappa \mathrm{B})$ signalling pathways in response to oxidative stress [36]. Witzmann and MonteiroRiviere demonstrated that MWCNTs could initiate inflammatory responses. Incubation of human keratinocytes with
MWCNTs reduced cell viability and a rise in proinflammatory cytokines was also noted [37].

Successful CNT application in the CNS depends on their biocompatibility with the CNS cells. There is much concern about their cytotoxicity as a result of their resemblance in structure with asbestos. Moreover, the biological application of CNTs requires their complete purification following their synthesis to eradicate both metal and carbonaceous particles that might be toxic to the cells and tissue [38]. It was demonstrated for the first time by $\mathrm{Ni}$ and colleagues [39] that the viability of the neurons from hippocampus incubated with copolymer-SWCNTs was not affected although there were changes in their morphology.

Gaiiiard and colleagues demonstrated the biocompatibility of functionalized MWCNTs with neuronal cells [40]. It was found that there was no effect of functionalized MWCNTs on the cell viability and neuronal architecture and normal function of primary neurons remained intact. In another study, neurotoxicity as a result of the presence of impurities from the metals during CNT synthesis was evaluated. The findings demonstrated that the impurities from iron in MWCNTs had a negative impact on cell viability and cytoskeleton. The ability of the neurons to produce mature neurites was reduced [41].

Cell viability in PC12 neuronal cells was impaired and damage on the cell membrane was observed during incubation of these cells with SWCNTs. Furthermore, there was a reduction in the potential of the mitochondrial membrane. SWCNTs triggered the formation of ROS and enhanced lipid peroxidation. Reduction in superoxide dismutase, glutathione peroxidase, catalase, and GSH was observed [33, 34]. Exposure of PC12 cells to SWCNTs was also demonstrated to lead to condensation of chromatin, fragmentation of nuclei, and blockage of cell cycle in G2/M phase [42]. These negative impacts were prevented by preincubation of the cells with vitamin E [43]. Toxicity to cells can be reduced by coating $\mathrm{CNTs}$ with surfactants or polymers like polypyrrole (PPy) to reduce direct contact between CNT and cells or tissues [44]. Further research on toxicity of carbon nanotubes has been summarized in Table 1.

Based on the research findings till date, it is impossible to decisively classify CNTs as toxic or nontoxic in vivo based on the fact that their impacts on cells rely on their application. It is indeed very difficult to draw clear conclusions about the toxicity of carbon nanotubes at the present moment. Nevertheless, they should be treated as toxic until further research confirms their classification.

\section{Chemically Functionalized Carbon Nanotubes for Biomedical Applications}

Carbon-based nanomaterials have limited dispersion in organic matrices as a result of their tendency to agglomerate due to their chemical inertness and van der Waals forces on their surfaces. Functionalization methods have been developed in order to eradicate this obstacle to augment biocompatibility [46]. Noncovalent and covalent functionalization are two procedures that are utilized to functionalize CNTs in 


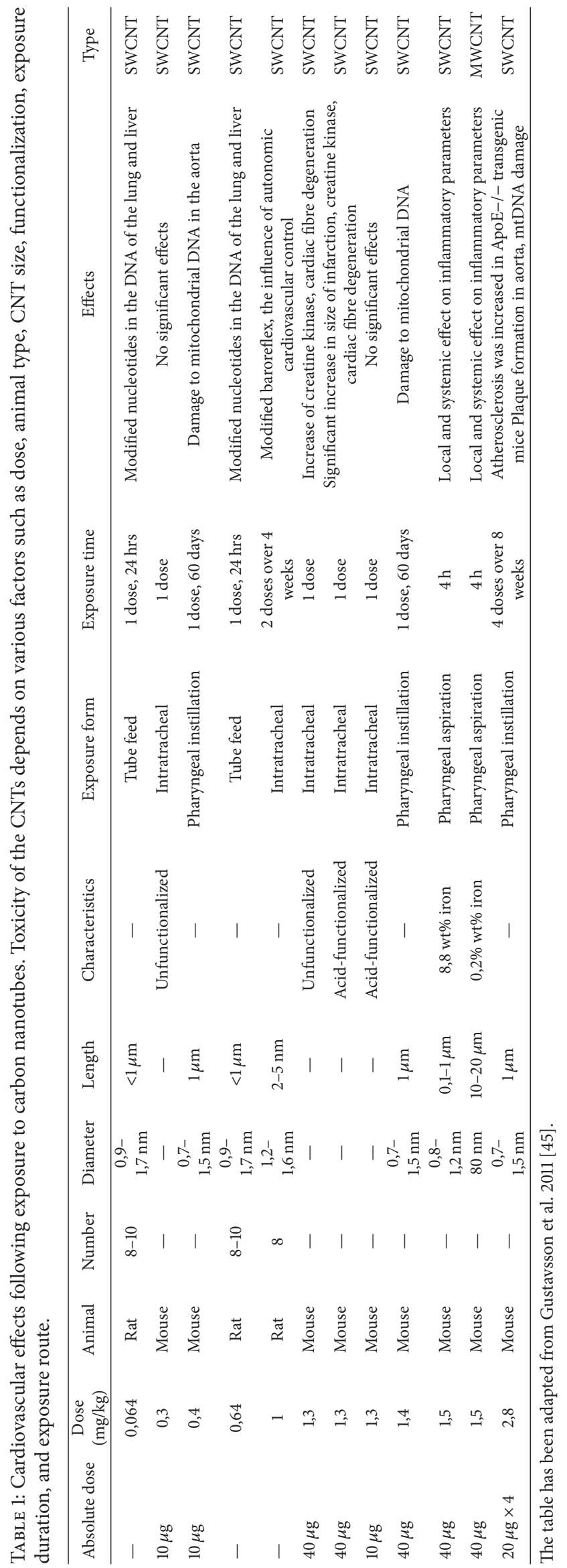




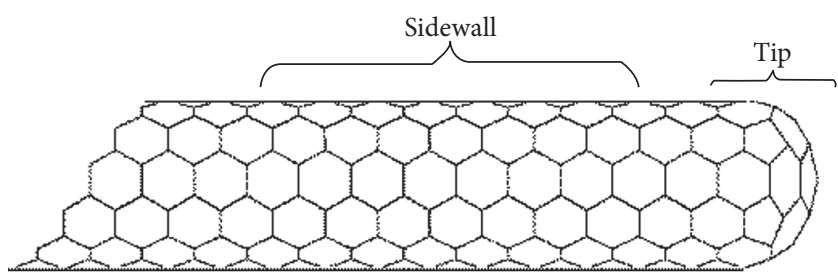

(a) CNT molecular structure with sidewalls and tips

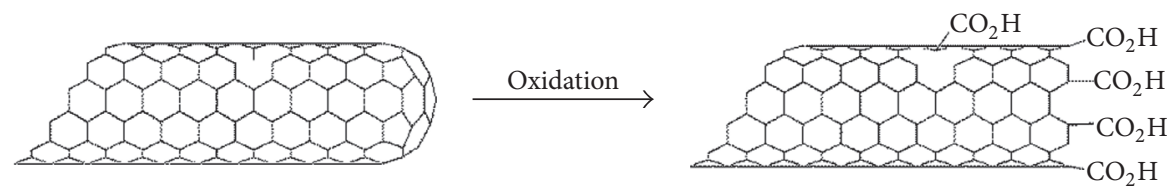

(b) CNT oxidation
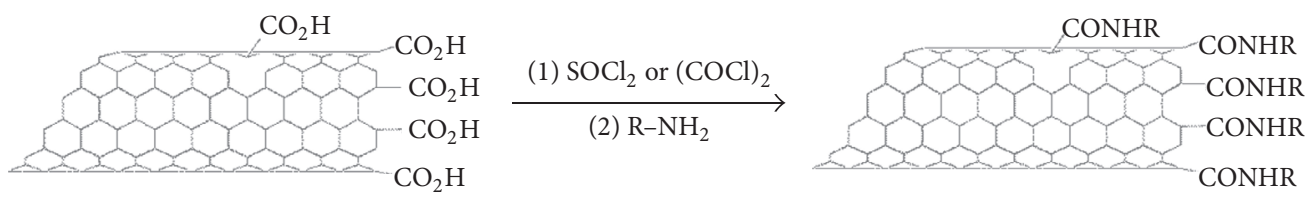

(c) Oxidized CNT amidation

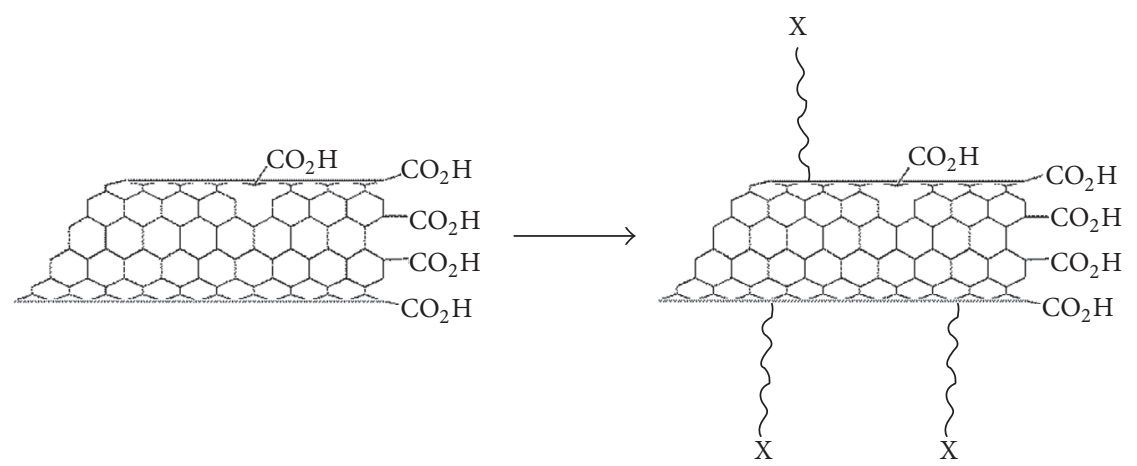

(d) CNT functionalization by addition reactions (X denotes functional group)
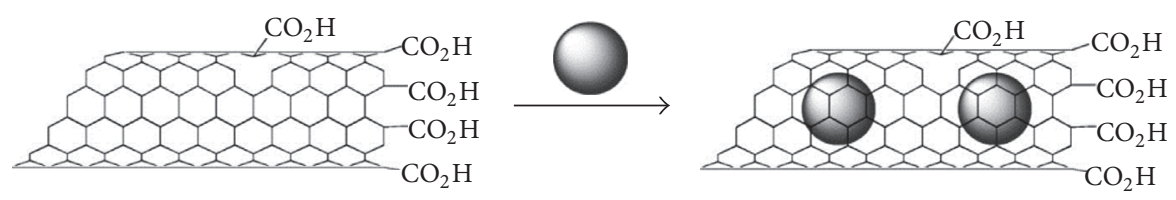

(e) Insertion inside CNTs

Figure 2: Oxidation and functionalization of CNTs. Pristine CNT has sidewalls and two tips (a). During oxidation carboxyl groups are attached to the sidewalls and tips (b). Oxidized CNTs are further functionalized by acylation, amidation, and addition reactions (c and d). Drug and fluorescent tags may be inserted inside the CNTs (e). Reproduced with permission from Prato and colleagues [14]. Copyright (2016) American Chemical Society.

order to enable their applications in a physiological environment $[17,45]$. These methods reduce agglomeration of native CNTs hence debundling and enabling easy handling of the CNTs (Figure 2).

In noncovalent functionalization, CNTs are coated with hydrophilic macromolecules with their hydrophobic groups attached to CNTs to create repulsive forces $[37,39,40]$. This is achieved by coating the CNTs with surfactants [47], polymers [48], peptides [49], and ssDNA [50]. The drawback of this method is the easy dissociation of the coating molecules from the CNTs.

In covalent functionalization, the charged group is coupled to the CNT backbone by organic reactions to create repulsive forces between individual nanotubes [18, 43-45]. Covalent functionalization is achieved by covalent coupling of functional groups on the sidewall and tip of the CNT. Functionalization on the sidewall involves chemical reactions by 1,3-dipolar cycloaddition. A highly soluble material was 
produced by attaching amino functional groups to the CNT sidewalls and tips $[17,18]$. This functionalization method is robust and does not have the dissociation challenge.

Functionalization is a pivotal procedure in achieving homogenous aqueous dispersion to tailor CNTs for biomedical applications $[6,46]$. This procedure modifies the physicochemical properties of the CNTs, their pharmacokinetic profiles, and biodegradability $[14,51]$. It was found earlier that pristine CNTs could not be metabolized and their persistence in vivo resulted in chronic inflammation. However, recent findings demonstrated the phenomenon of oxidized SWCNT biodegradation in neutrophils and macrophages, with no inflammatory response following aspiration of CNTs into the lungs of mice [52].

The biodegradation process of chemically functionalized CNTs has been shown to be mediated by an oxidative milieu in phagocytic cells and this has been demonstrated in in vivo and ex vivo studies $[6,50]$. Functionalized CNTs should therefore not be regarded as toxic based on these findings. Pristine CNTs have been found to have a tendency of agglomeration and accumulation in reticuloendothelial system (RES) while functionalized CNTs were better tolerated $[14,47]$. Pristine and functionalized MWCNTs accumulated in RES following 30 min intravenous injection whereas only pristine CNTs were retained for months in the liver and lungs. Functionalized CNTs (fCNTs) were easily cleared from the body via excretion in the urine and further investigations confirmed these findings $[48,49]$.

Various types of chemical groups, for example, hydrophobic, hydrophilic, neutral, and charged, have an impact on the dispersibility of the functionalized CNTs (fCNTs) as illustrated in Table 2. The debundled fCNTs do not trigger inflammatory responses as observed in the bundled pristine and fCNTs [53]. Functionalization degree has an effect on cytotoxicity of CNTs and this was demonstrated by Ji and colleagues [54] and Jain and colleagues [55]. Single-dose injections of pristine MWCNTs and low level functionalized CNTs induced liver damage in mice which became apparent 7 days after treatment. Mice with single-dose injections of CNTs with a high level of functionalized groups did not display any toxicity in the work undertaken by Jain and colleagues [55]. Metal impurities associated with CNTs during synthesis also contribute to cytotoxicity and this could be mitigated by acidoxidation of CNTs to remove the metals [55].

It is thus imperative to modify CNTs chemically by oxidation and amidation to couple functional groups to CNTs in order to overcome their toxic effects. Nonhomogeneity of the coupled functional groups on the surface of the fCNT may cause this approach to be suboptimal for biomedical applications $[74,75]$. Polyethylene glycol (PEG) is most commonly utilized to augment CNT blood circulation to achieve stable and well dispersed drug delivery systems [76].

The PEGylation mechanism of action with regard to CNTs is not clear at the current stage but PEG plays a pivotal role in reducing opsonin binding to CNTs and hence causes a reduction in early CNT removal from the blood circulation [77]. Polymers such as PEG tend to adopt different confirmations when they are attached to CNTs. A brushlike conformation when PEG is coupled to SWCNTs reduces
CNT blood circulation and increases renal clearance and relative spleen versus liver uptake as opposed to PEG with a mushroom conformation [78].

Furthermore, the functionalization process, which includes the level of functionalization, surface density, and homogeneity of the functional group, contributes significantly to the success of CNT application in the biomedical field [76]. Cirillo and colleagues performed CNT covalent functionalization with a molecule of biomedical interest, namely, gallic acid, for the first time [79]. Gallic acid is a natural antioxidant found in various vegetables and possesses antiallergic, antimutagenic, anti-inflammatory, anticarcinogenic, and radical scavenging activities. Gallic acid-functionalized CNTs were found to be effective in reducing oxidative stress in biological environment $[55,57,64]$.

Transport of fluorescein isothiocyanate- (FITC-) MWCNTs across immortalized murine microvascular cEND cells using Transwell device was investigated by Shityakov and colleagues. It was found that the FITC-MWCNT aggregates were nonfluorescent and localized on the surface of the cell whereas the dispersed FITC-MWCNTs were fluorescent and localized intracellularly as well as on the cell membrane [80].

Oxidation of CNTs can also be undertaken which yields pure and shorter CNTs using a strong oxidizing agent such as nitric acid. The carboxylic acid groups might be coupled to the carbon nanotubes and be further functionalized by coupling with ester and amide groups. The enhanced attainment of CNT dispersibility has widened the extent of their application in physiological systems from diagnostics and therapeutics in oncology $[54,73,81]$ to neuroprosthetic devices [7679].

Functionalization can therefore be applied in carbon nanotubes to convert their hydrophobic nature to hydrophilic nature. In addition, their toxicity has been found to be reduced or eliminated following functionalization as demonstrated from the findings summarized in Table 2.

\section{Carbon Nanotubes as Electrochemical Biosensors in Neuroscience}

There are two types of biosensors, namely, CNT field effect transistors (CNT-FET) and CNT-electrochemical sensors. In CNT-FET, the conductive channel can be SWCNTs and this system has been proven to have superior performance by Fam and colleagues [82]. The CNT-FET biosensors have high sensitivity; hence, they are suitable for detection of very low concentrations of analytes in the sample.

The detection of chemical redox interactions has been performed by CNT-based electrochemical biosensors. The CNT unique properties, such as electrical conduction and small size in particular, are preferred since they enable them to act as electrodes with direct contact to the physiological environment. CNT electrochemical biosensors have been utilized successfully for detection of enzymes, $\mathrm{H}_{2} \mathrm{O}_{2}$, DNA, RNA, proteins, glucose, and many other biomolecules. CNT functionalization plays a vital role in augmenting the specificity of the electrochemical biosensors [70, 83].

Carbon-based electrochemical sensors have been used widely for neurotransmitter analysis due to surface oxides, 
TABLE 2: Functionalized carbon nanotubes and reduced cytotoxic effects. Different functional groups on MWCNTs and SWCNTs have different toxic effects on different cell types and animal types.

\begin{tabular}{|c|c|c|c|c|}
\hline Functional group or structure & Toxicological studies & Application & Target site & Reference \\
\hline Acid-oxidized SWCNTs & $\begin{array}{l}\text { Apoptosis studies showed } \\
\text { no apparent cell toxicity }\end{array}$ & $\begin{array}{l}\text { Intracellular protein } \\
\text { transporters }\end{array}$ & Mammalian cells & Kagan et al., 2010 [52] \\
\hline $\begin{array}{l}\text { Acid-treated, water-soluble } \\
\text { SWCNTs }\end{array}$ & $\begin{array}{c}\text { No changes in cell } \\
\text { viability or structure in } \\
\text { lysosomes and cytoplasm }\end{array}$ & & $\begin{array}{c}\text { Human } \\
\text { monocyte-derived } \\
\text { macrophage cells }\end{array}$ & Keefer et al., 2008 [56] \\
\hline Purified COOH-SWCNTs & No cytotoxicity & $\begin{array}{l}\text { Pharmacological } \\
\text { applications }\end{array}$ & $\begin{array}{c}\text { Cultured } \\
\text { mammalian cells }\end{array}$ & Al-Jamal et al., 2012 [57 \\
\hline Oxidized ultrashort SWCNTs & $\begin{array}{c}\text { Showed no cytotoxic } \\
\text { effects }\end{array}$ & $\begin{array}{l}\text { Intracellular delivery of } \\
\text { oligonucleotide } \\
\text { molecules }\end{array}$ & $\begin{array}{c}\text { Human } \\
\text { macrophages }\end{array}$ & Cellot et al., 2009 [58] \\
\hline Amine-terminated CNTs & $\begin{array}{l}\text { Cross cellular membrane } \\
\text { without cytotoxicity }\end{array}$ & $\begin{array}{l}\text { Delivery of amino acids, } \\
\text { peptides, nucleic acids, } \\
\text { or drugs }\end{array}$ & & $\begin{array}{l}\text { Webster et al., } 2013 \text { [59] } \\
\text { Shein et al., } 2009 \text { [60] } \\
\text { He and Dai, } 2004 \text { [61] }\end{array}$ \\
\hline SWCNT-PL-PEG & $\begin{array}{l}\text { Gene silencing with no } \\
\text { apparent cytotoxic effects }\end{array}$ & $\begin{array}{l}\text { SH-small interfering } \\
\text { RNA delivery }\end{array}$ & Human T cells & Modi et al., 2010 [2] \\
\hline SWCNT-PEG-drug & $\begin{array}{l}\text { Decreased reactive } \\
\text { oxygen species mediated } \\
\text { toxicological response and } \\
\text { exhibited less cytotoxicity }\end{array}$ & Drug delivery & $\begin{array}{l}\text { Neuronal PC12 } \\
\text { cells }\end{array}$ & $\begin{array}{c}\text { Grossman and } \\
\text { Broderick, } 2013 \text { [10] }\end{array}$ \\
\hline $\begin{array}{l}\text { SWCNT-PEG- } \\
\text { cisplatin/doxorubicin }\end{array}$ & $\begin{array}{l}\text { Remarkable reduction of } \\
\text { cytotoxicity }\end{array}$ & $\begin{array}{l}\text { Drug delivery and } \\
\text { imaging tool }\end{array}$ & $\begin{array}{l}\text { Human cancer } \\
\text { cells/mice }\end{array}$ & $\begin{array}{c}\text { Sharma et al., } 2013 \text { [62]; } \\
\text { Ansari et al., } 2011 \text { [19] }\end{array}$ \\
\hline SWCNT-PEG-mAb $(\alpha \mathrm{v} \beta 3)$ & $\begin{array}{c}\text { Without harming adjacent } \\
\text { normal cells }\end{array}$ & Cancer-cell targeting & $\begin{array}{l}\alpha \mathrm{v} \beta 3 \text {-positive } \\
\text { U87MG cells }\end{array}$ & Tan et al., 2012 [63] \\
\hline SWCNT-PEG & $\begin{array}{l}\text { Revealed no evidence of } \\
\text { toxicity over } 4 \text { months }\end{array}$ & Mice & & Kotchey et al., 2013 [64] \\
\hline MWNT-CS-(PC) & $\begin{array}{l}\text { Chitosan and PC reduced } \\
\text { the cytotoxic effects on } \\
\text { normal cells with specific } \\
\text { photo-induced toxicity } \\
\text { towards malignant cells }\end{array}$ & Photothermal therapy & $\begin{array}{l}\text { MCF-7, HepG2, } \\
\text { L-O2 cell lines }\end{array}$ & John et al., 2015 [65] \\
\hline $\begin{array}{l}\text { Polyoxyethylene sorbitan } \\
\text { monooleate (PS80) CNTs }\end{array}$ & Suppressed cytotoxicity & & $\begin{array}{l}\text { Human lung } \\
\text { mesothelium cells } \\
\text { (MSTO-211-H) }\end{array}$ & Zheng et al., 2003 [50] \\
\hline $\begin{array}{l}\text { HMDA-SWCNTs; PDDA } \\
\text { chloride-SWCNTs }\end{array}$ & $\begin{array}{l}\text { Negligible cytotoxic } \\
\text { effects }\end{array}$ & $\begin{array}{l}\text { Intracellular delivery of } \\
\text { negatively charged } \\
\text { biomolecules }\end{array}$ & Rat heart cells & Pardridge, 2012 [66] \\
\hline $\begin{array}{l}\text { SWCNTs with human serum } \\
\text { proteins }\end{array}$ & $\begin{array}{l}\text { Blood proteins altered } \\
\text { SWCNT cellular } \\
\text { interaction pathways and } \\
\text { reduced cytotoxicity }\end{array}$ & Biological applications & $\begin{array}{c}\text { Human acute } \\
\text { monocytic } \\
\text { leukemia cell lines } \\
\text { and human } \\
\text { umbilical vein } \\
\text { endothelial cells }\end{array}$ & Ciccone et al., 2011 [16] \\
\hline BSA-dispersed SWCNTs & $\begin{array}{l}\text { No acute deleterious } \\
\text { cellular effects }\end{array}$ & & $\begin{array}{c}\text { Human } \\
\text { mesenchymal stem } \\
\text { cells and HeLa cells }\end{array}$ & $\begin{array}{c}\text { Ben-Jacob and Hanein, } \\
2008 \text { [67] }\end{array}$ \\
\hline Albumin-SWCNTs & $\begin{array}{c}\text { Induced cyclooxygenase-2 } \\
\text { and modulating toxicity } \\
\text { effects of SWCNTs }\end{array}$ & & $\begin{array}{l}\text { RAW264.7 } \\
\text { macrophage cell } \\
\text { lines }\end{array}$ & $\begin{array}{c}\text { Malarkey et al., } 2009 \\
{[68]}\end{array}$ \\
\hline DNA-encased MWCNTs & $\begin{array}{l}\text { Does not exert cytotoxic } \\
\text { effect on lymphocytes }\end{array}$ & $\begin{array}{l}\text { Selective thermal } \\
\text { ablation of malignant } \\
\text { tissue in vivo }\end{array}$ & In vivo & Vidu et al., 2014 [69] \\
\hline Lectin-functionalized CNTs & $\begin{array}{l}\text { Increase in cell viability } \\
\text { without signs of apoptosis }\end{array}$ & Nanovaccine fabrication & $\begin{array}{l}\text { J774A macrophage } \\
\text { (MOs) cell line }\end{array}$ & $\begin{array}{c}\text { Kesharwani et al., } 2012 \\
{[70]}\end{array}$ \\
\hline
\end{tabular}


TABLE 2: Continued.

\begin{tabular}{lcccc}
\hline Functional group or structure & Toxicological studies & Application & Target site & Reference \\
\hline $\begin{array}{l}\text { Fluorescent CNT-FITC/biotin } \\
\text { conjugates }\end{array}$ & Reduced cytotoxicity & Delivery systems & HL60 cells & Nho et al., 2010 [71] \\
Cationic fCNTs & $\begin{array}{c}\text { Lowered cytotoxicity in } \\
\text { vitro }\end{array}$ & $\begin{array}{c}\text { Delivery of drugs and } \\
\text { biomolecules }\end{array}$ & $\begin{array}{c}\text { CHO, 3T3 fibroblast, } \\
\text { Jurkat, HL60 cell lines }\end{array}$ & Kim et al., 2012 [72] \\
\hline
\end{tabular}

Adapted from Vardharajula et al. 2012 [73].

CNTs = carbon nanotubes; fCNTs = functionalized carbon nanotubes; SWCNTs = single-walled carbon nanotubes; PL = phospholipid; PEG = poly $($ ethylene glycol); $\mathrm{mAb}=$ monoclonal antibody; MWCNTs = multiwalled carbon nanotubes; CS = chitosan; PC = phycocyanin; CTAB = cetyltrimethylammonium bromide; $\mathrm{HMDA}=$ hexamethylenediamine; $\mathrm{PDDA}$ = polydiallyldimethylammonium; $\mathrm{BSA}$ = bovine serum albumin.

facilitating electron transfer and readily adsorbing neurotransmitters due to electrostatic interactions. Functionalized CNT electrodes have been used for neurotransmitter detection with high sensitivity and selectivity. Vertically aligned CNTs can lead to more reproducible surfaces with CNT ends exposed to enhance sensitivity [84]. CNT yarns are made of multiple CNT fibres twisted together and these have been utilized by Yang and team for production of CNT yarn microelectrodes (CNTYMEs). The CNTYMEs are used for speedy measurements of dopamine [85].

CNTs can be used to determine the level of disease severity and other pathological conditions. CNTs are utilized as artificial smart intelligent tools such as nanosensors which are designed in such a way so as to easily implant them in the body. These devices are capable of detecting a slight change in a physiological condition and may be used for qualitative and quantitative work. CNTs are used to design pressure nanosensors due to their physical properties [86].

Biosensors, nanosized materialistic devices applied in the detection of biological disorders of human bodies, are manufactured from CNTs. Sotiropoulou and Chaniotakis have demonstrated that MWCNTs with vertical alignment can be used as substrates to develop an amperometric biosensor [87]. The use of CNT-based nanobiosensors enables the detection of DNA sequences in the body and this may play a crucial role in the cancer treatment and other diseases [56, 88, 89]. Bionanosensors are also applied in determination of blood glucose levels, monitoring of blood pressure, detection of potassium and sodium, and measurement of blood $\mathrm{pH}$. Furthermore, CNTs can be used in measurement of respiratory gases.

Ghosh and colleagues demonstrated that SWCNTs can be used to design heart pacemakers with energy saving mechanism [90]. CNTs presented themselves as excellent candidates for the development of electrodes, namely, microelectrode arrays (MEAs), based on their large surface area and outstanding electrical conductivity $[8,58,76,77,82]$. MEAs consist of metallic microelectrodes inserted in a substrate which is well aligned and connected to an electrical circuit. Neural electrical activity can be stimulated in a noninvasive manner using individual microelectrodes. MEAs are biocompatible and have a large signal to noise ratio [46]. CNTs synthesised on silicon dioxide substrates enhanced the electrical properties of CNT-MEAs [91].

Shein and colleagues confirmed that the MEAs tool was capable of measuring the spontaneous activity in the rat cortical neuron [60]. Neurons were cultured on MEAs in which CNTs were deposited. Lin and colleagues were the pioneers in the synthesis of CNT electrode arrays on silicon substrates. The success in this work inspired Lin and colleagues to modify it for easy use. The system was applied in recording the action potentials of nerves from crayfish [92]. There is a limited understanding of the interaction of CNTs and the CNS and their potential application requires further investigation as a result [93].

SWCNTs are fluorescent in the spectral region of 700$1100 \mathrm{~nm}$ with minimal interference from biological media. They have been functionalized for biocompatibility, stability, and selective molecular recognition by Iverson and team for use as in vivo biosensors [94]. The functionalized SWCNTs were injected via the tail vein of the mouse and circulation time and biodistribution studies were performed. Nitric oxide produced during inflammation in vivo was detected and the sensor was found to be stable for years. These findings have demonstrated the potential of these SWCNTs to be utilized as in vivo biosensors for biomarkers of various inflammatory diseases including ischemic stroke.

MWCNTs functionalized with diethylene triaminepentaacetic acid and labeled with indium were delivered into the brain by intravenous injection via mouse tail vein for biodistribution studies [95]. DTPA- ${ }^{111}$ In MWCNTs were retained in the brain parenchyma for 24 hours following intravenous injection while the levels in the blood capillaries diminished considerably. These findings have demonstrated that functionalized MWCNTs could be delivered to the brain parenchyma via intravenous injection. Based on these findings, CNTs have the potential to be used as vehicles to transport molecules and therapeutics to the brain for targeting and neurological disease treatment including ischemic stroke.

The findings demonstrate the potential of carbon nanotubes for use in the fabrication of carbon-based sensors for the detection of biomarkers of various diseases including neurological and ischemic disorders.

\section{Carbon Nanotubes as Imaging Tools in CNS for Localization and Detection of Ischemic Stroke}

CNTs are very useful in imaging of the tissues for location of the diseased site and delivery of drug to the site of action $[61,96]$. Imaging is a pivotal tool in the study of physiological and biochemical activities in the CNS, for the brain and spinal 


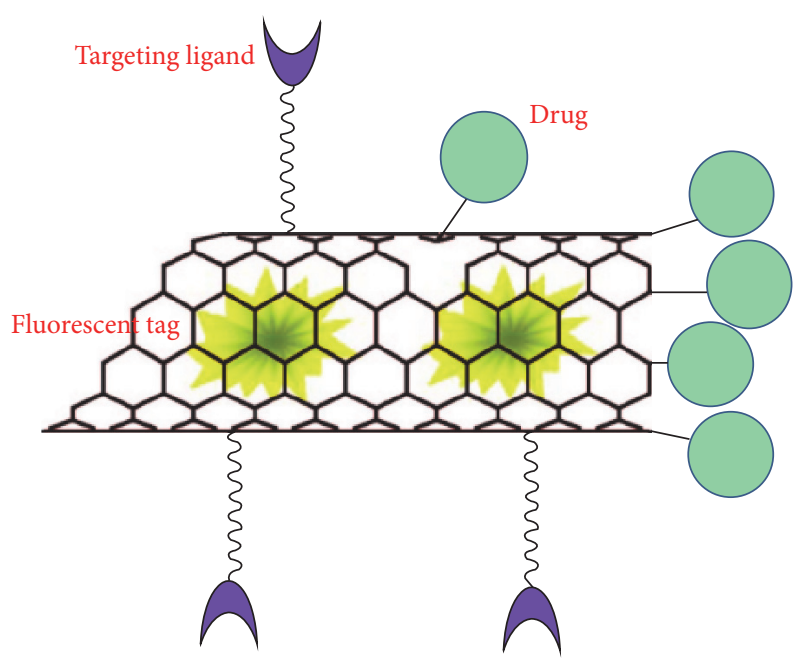

FIGURE 3: CNT equipped with a targeting ligand, drug, and fluorescent tag. A drug of interest is coupled to carbon nanotube. A targeting ligand such as monoclonal antibody is attached to the carbon nanotube for targeting the site of interest. Fluorescent tag is also coupled to carbon nanotube either externally or internally for localization of the targeting ligand-drug complex. Reprinted with permission from Prato and colleagues [14]. Copyright (2016) American Chemical Society.

cord, in particular. Technological advancements in this area improved understanding of the effect of cellular damage on the CNS. The precision of neurological interventions and reduced invasiveness to the CNS have been enhanced to a greater extent [97]. The current technologies in CNS imaging include electroencephalography and magnetoencephalography. In these techniques, electrodes are placed on the skull to measure electrical signals coming from the brain. The skull is surgically opened to gain access to the brain to insert electrodes for the measurement of the signals directly from the brain. This technique is very invasive and it requires an alternative noninvasive approach.

Methotrexate has been demonstrated in cancer imaging to improve visibility in the body when coupled with fluorescein probe-functionalized CNTs (Figure 3). This system could be tailored for use as an imaging tool for localization of ischemic site and treatment of ischemic stroke.

A longer excitation time is achieved at higher laser intensity when SWCNTs are utilized as a result of their high photostability as opposed to quantum dots and fluorophores [69]. Fluorescence, absorption, and scattering characteristics of a biological material enable the visibility of the opaque tissue in the range of 700-1400 nm. CNTs enhance the visibility since they allow imaging of the entire thick tissue [98]. CNTs have large resonance and enhanced Raman scattering properties; hence, they can be easily detected [99].

The imaging techniques, namely, magnetic resonance imaging, position emission tomography, and computer tomography, have led to a better understanding of neuronal circuit functioning. Despite their benefits, they do have drawbacks which include lack of sensitivity, inability to permeate the $\mathrm{BBB}$, and reduction of half-life following intravenous administration [13]. Miniaturized video devices can be encapsulated into CNTs and be administered orally to assist in imaging the diseased site within a tissue [86].

Biomedical imaging has a vital role to play in both testing the efficacy of new therapies and investigating their biodistribution. Attaching radionuclide labels onto CNTs allows three dimensional (3D) whole body, in vivo molecular imaging such as position emission tomography (PET), and single photon emission computed tomography (SPECT). These techniques have high sensitivity and moderate resolution and have the advantage of being well established medical techniques.

Hong and colleagues reported the first noninvasive brain imaging in a narrow $1.3-1.4 \mu \mathrm{m}$ region (named as the NIRIIa region). This procedure allows penetration through intact scalp and skull and resolves cerebral vasculatures with previously unattainable spatial resolution of sub-10 $\mu \mathrm{m}$ at a depth of $>2 \mathrm{~mm}$ underneath the surface of the scalp skin in an epifluorescence imaging mode. Furthermore, dynamic NIRIIa cerebrovascular imaging with high temporal resolution ( $<200 \mathrm{~ms} /$ frame) was used to reveal drastically reduced blood flow due to arterial occlusion in an acute stroke model on mice [100].

The findings confirm that carbon nanotubes have a potential to be used as noninvasive imaging tools in the brain disorders.

\section{Carbon Nanotubes as CNS Drug Delivery Vehicles for the Treatment of Ischemic Stroke}

Stereotactic surgery is an invasive procedure which is clinically used for delivering drugs and other biologically important molecules into the brain. This procedure paves a way to direct access to the specific site of interest within the brain $[67,85]$. Application of nanodrug delivery could be of great benefit in the future for neuroprotection success in chronic neurological diseases including ischemic stroke (Figure 4).

Delivery of drugs through the BBB could be attained by application of nanotechnology [62]. Nanotechnological advances for neurotrophin delivery systems are promising regarding their ability to activate neurotrophin signalling for neuroprotection and neuroregeneration [63]. Neurotrophins are indispensable for the development and functions of neurons and can be delivered to their site of action by CNTs $[92,93]$.

Use of CNTs as delivery vehicle for CNS disease treatment is dependant on their physicochemical properties, mainly their improved solubility in physiological solvents due to their functionalization, large surface area, ability to be easily modified with drug molecules, and biocompatibility with the neural system [65]. Antitumour drug molecules have very low permeability across the $\mathrm{BBB}$ and this poses a negative impact on brain tumour treatment.

Iverson et al. [94] used CNT drug delivery system to enhance $\mathrm{CpG}$ oligodeoxynucleotide immunotherapy in the treatment of glioma. SWCNTs were functionalized with PEG followed by conjugation with $\mathrm{CpG}$ oligonucleotide. Toll-like 


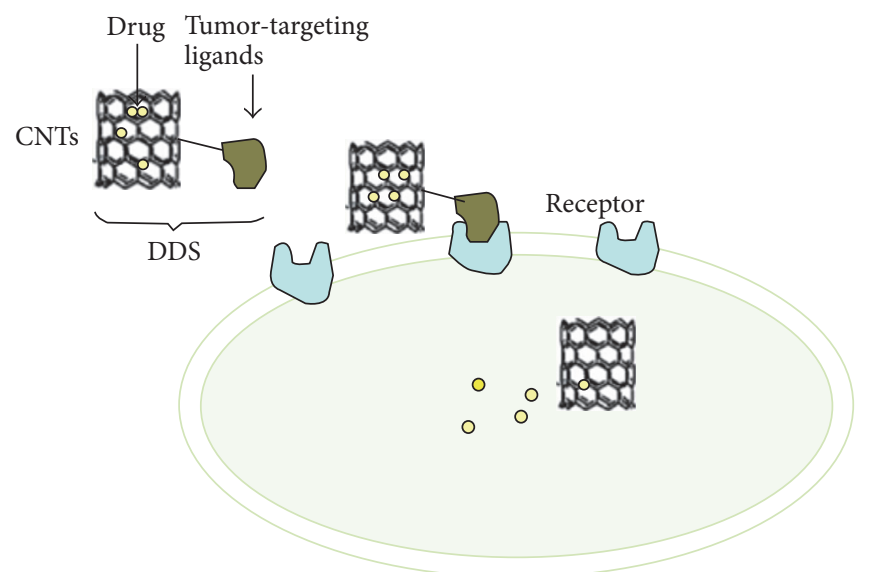

FIGURE 4: Drug delivery system (DDS). An antitumour drug and tumour-targeting ligands are coupled to carbon nanotubes (CNTs). Tumourtargeting ligands bind to the receptors on the cell membrane and the DDS is transported into the cell. Drug is released from the CNTs into the cell as a result of an acidic milieu. Adapted from Ji and colleagues [15].

receptor (TLR) family members are located intracellularly and recognize lipids, carbohydrates, nucleic acid structures, and peptides expressed by microorganisms. When $\mathrm{CpG}$ was conjugated to SWCNTs, there was an enhancement of the uptake of $\mathrm{CpG}$ in both in vivo and intracranial gliomas. CpG stimulated TLR in the glial cells to inhibit tumour growth in glioma models [101]. Yang and colleagues had also shown that CNTs are able to cross BBB for acetylcholine delivery into neurons of mice for Alzheimer's disease treatment [102].

Neurotherapy with the use of CNTs would be extremely useful in the treatment of various neurological pathologies including ischemic stroke. SWNCNT functionalized with amine groups via amidation reaction enhances the tolerance of neurons to ischemic injury. Neurons are protected from injury and their functions are also regained with aminemodified SWCNTs without therapeutic intervention [103]. Al-Jamal and colleagues demonstrated the effectiveness of amine-MWCNTs in delivery of small interfering RNA (siRNA) that decreased apoptosis at the injury site and promoted recovery of functional motor neurons in a mouse model of endothelin-1 stroke [104].

The presence of the $\mathrm{BBB}$ poses a major problem in transporting drugs to the brain for tumour treatment and other neurological disorders including stroke. The BBB is rigorously selective and permits a very small amount of substances in the blood circulation to gain access to the CNS [98, 99]. It prevents therapeutic molecule delivery into the CNS resulting in delivery of less than $1 \%$ of the administered drug through intravenous injection to the CNS $[100,105]$. This intensive selection of substances into the brain plays a crucial role in the regulation of homeostasis of the CNS. Moreover, it protects the CNS from invasion by foreign material such as toxins, viruses, bacteria, and other unwanted substances $[15,62,63,100]$.

Neuroprotection could be achieved in the future by use of nanodrug delivery in chronic neurological disorders. Neurotrophins are proteins involved in neuroprotection. Neurotrophins are essential for the development and function of neurons in both CNS and PNS. They can be delivered into the brain using CNTs. The use of CNTs as a delivery mechanism for the treatment of CNS pathology is based on their structural features, especially their improved solubility in physiological solvents due to their functionalization, large surface area, ability to be easily modified with drug molecules, and biocompatibility with neural systems [65]. Carbon nanotubes, therefore, have demonstrated their potential to be used as delivery vehicles of drugs to the diseased site in the brain.

\section{Carbon Nanotubes in Neuroengineering in Ischemic Stroke and Other CNS Disorders}

CNT use in neuroengineering scaffolds is an emerging technology. Neural tissue engineering contributes significantly to developing and improving biological scaffolds to promote neural tissue functioning [97]. Neural tissue engineering is a promising approach in recovery from neurodegenerative disorders including stroke. Research in this field is extensive to create an effective scaffold for the development of neural networks.

There are two types of scaffold: CNT-scaffolds and CNTcomposite scaffolds. A major challenge in the development of scaffolds is the limited methods for the production of scaffolds with the structure of interest. The advantage of the scaffolds is that they provide undiluted CNT physicochemical properties. Promising results recommend CNTs to be the most relevant substrate for neural tissue growth, aiding in repair and regeneration of damaged neurons, although research work in this area is currently in the early stages. Incorporation of CNTs into scaffolds facilitates interfacing of neurons with CNTs hence stimulating neurons electrically to reestablish neural interconnections [106].

Kuzmenko and colleagues developed an effective method of scaffold fabrication for neuronal engineering [107]. This method utilizes a renewable resource as a precursor and exploits the advantages of an electrospun architecture 
together with conductive functionalization. All the scaffolds provided attachment and growth of neural cells. CNTs can act as substrates for the successful repair of damaged neurons since they can integrate with neurons to promote their functions due to their biocompatibility and electromechanical properties $[3,101]$.

Development of an effective scaffold depends entirely on its biocompatibility with the cells of interest and the surrounding cells. Several in vitro biocompatibility studies of CNTs were conducted by optimizing the conditions with the main focus on CNT concentrations, purity status, functionalization type, and CNT composites. Biocompatibility studies involve loose CNTs in suspension and physically contained within a structure [108].

CNTs may be functionalized with carboxyl groups, polymers, and sugars to facilitate growth and adhesion properties of cells. It was demonstrated that acid-functionalized MWCNTs enhanced neuronal neurite outgrowth in neurons and rat pheochromocytoma cell line in culture media supplemented with nerve growth factor [8]. Cellular interactions with a scaffold could be affected by the size and structure of the scaffold generated from CNTs [109].

The human mesenchymal stem cell (hMSC) growth can be directed by various patterns of CNTs. Fibronectin-CNTs promoted hMSC growth and differentiation whereas carboxylated-CNTs had negative impact on the stem cells growth and differentiation [109]. Heterostructures can be produced by addition of CNTs to polymer compounds for scaffolding. CNTs are dispersed with PEG and poly(propylene fumarate) (PPF) to produce porous polymer composites. Porous polymers become electrically conductive following dispersion of CNTs and this may result in stimulation of cell growth [109]. These composites have been used to enhance bone regeneration and also neural regeneration $[103,104]$.

The CNS of mammals has very little auto-repair capability and as a result there is a need for neural stem cells and human mesenchymal stem cells transplantation for recovery of functioning of neurons following neurodegenerative diseases and CNS injuries including stroke [110]. Mesenchymal and neural stem cells interacted well with vertically aligned CNTs and growth on arrays was successful [71]. The hMSC differentiation was enhanced in the presence of MWCNT sheets when these cells were grown on CNT sheets [72].

CNTs can be utilized in stem cell transportation to CNS for treatment of damaged neuronal tissue in stroke victims since they have been proven to have the capacity to enhance differentiation of neural stem cells. CNTs contribute significantly to the advances in tissue engineering for repair of damaged tissues as a result of their mechanical strength and electrical conductivity and resemblance to neurites [110].

Neural stem cells were used to assess their preferred growth environment and it was found that they had enhanced growth in CNT environment compared to in a polyurethane surrounding [71]. CNTs are not degraded in a biological environment; thus CNTs can be utilized as implants for long-term intervention following injury in the brain and spinal cord. PC12 cells and hippocampal neurons were cultured on carbon threads from SWCNTs and the growth was successful, further confirming biocompatibility. Nanothreads can be used for development of electrodes or nanowires which can be used in implantable devices due to their biocompatibility characteristics.

Biomaterials science and stem cell biology integration in the brain of the ischemic mouse was performed by Stockwell and colleagues [111, 112]. The use of polyglycolic acid in scaffolding provides a platform for integration of multipotent stem cells and contributes to damaged neural tissue restoration. CNTs that were impregnated with neural progenitor cells enhanced differentiation of those cells. The cells migrate to the injured tissue to restore the damaged tissue around the ischemic core region [113].

Nanofibers and stem cell combination improved efficacy for neuronal function restoration in stroke models. Impregnation of carbon nanofibers promoted differentiation of neural stem cells after being injected into brains of the rats induced with stroke and this procedure had also resulted in glial tissue formation $[108,114]$. The ability of CNTs to trigger differentiation of neural stem cells to neurons implies that CNTs have a potential to be utilized as a vehicle to transport stem cells to the damaged neural tissues for treatment of stroke. Roman and colleagues demonstrated that CNTs play a pivotal role in the treatment of brain and spinal cord injuries [115]. Direct injection of PEG-SWCNTs was demonstrated to enhance restoration of damaged axons in rat spinal cords with lesion at $\mathrm{T} 9$.

The two main approaches to promoting auto-repair of damaged connections in axons are axonal regrowth and neuronal circuitry reorganization. The requirements for successful regenerative engineering are neurorestoration, neurogenesis, reconnection of neuronal circuits, and neuroplasticity $[92,116]$. It has been demonstrated for the first time by Mattson and colleagues that neurons of rat hippocampus could be grown on MWCNT layer functionalized with 4hydroxynonenal [117]. Furthermore, functionalization of the surface of CNTs has been demonstrated to have an impact on the growth patterns of the neurites, lengthening, branching, and the number of growth cones.

It has been shown by $\mathrm{Hu}$ and colleagues that functionalization of positively charged MWCNTs with polyethylenediamine led to a rise in the number of growth cones and neurite branches in neurons [118]. SWCNTs that have been chemically modified with the cationic polymer, polyethylenediamine (PEI), were found to enhance growth of neurites and the number of branches as opposed to PEI alone [118]. Matsumoto and colleagues functionalized MWCNTs with brain derived neurotrophic factor to promote growth and differentiation of neurons [119]. The mechanism of action by which neurons reconstruct and rebuild active synapses in the presence of CNTs is not known [120].

Since CNTs have the capability to stimulate growth and differentiation of neurons, in vitro studies have triggered the interest of translating this work into in vivo outcomes in order to enhance motor functional recovery from ischemic stroke in rats or mice. Implantation of CNTs coupled to neural progenitor cells at the diseased sites in the brain of strokeinduced rat led to reduction of the infarct cyst volume and a rise in neuronal markers when compared to untreated neuronal progenitor cells [113]. 
The CNT potential in neurodegeneration application has been envisaged. However, CNT-based neuroregenerative approaches are still far from clinical application as a result of major concerns linked to their toxicity, degradation, and safe use. There is an evidence that an appropriate functionalization and administration route can make CNTs biocompatible and biodegradable thus shortening the way to clinical trials [30].

\section{Recent Advances in Ischemic Stroke Treatment}

Short interference RNAs (siRNAs) have the ability to disperse CNTs by a wrapping mechanism. The siRNAs are composed of hydrophobic bases and alternative hydrophilic phosphates and riboses. Such structure facilitates CNT dispersion by the bases wrapping to CNTs and the hydrophilic sugar-phosphate groups extending to the water phase [121]. Dispersibility promotes the interaction of siRNA with the living cells and tissues.

The siRNA knocks out apoptotic genes resulting in silencing and inhibition of these genes, hence an effective stroke treatment $[117,122]$. Direct siRNA delivery to the CNS enhanced the efficacy of siRNA in treating neurological disorders in animal models $[118,119]$. Sufficient siRNA delivery is needed direct to the diseased tissues and cells to maintain effective silencing of gene. This is regarded as a major obstacle because high siRNA doses are required to be administered into the CNS by continuous pump infusion. Neuronal tissue damage and apoptosis may be induced by electroporation techniques and lipid transfection reagents [120,121].

Al-Jamal and colleagues used functionalized CNTs to deliver caspase-3 siRNA into the brain of the rat via stereotactic injection. Neurodegeneration was reduced and functional preservation was enhanced in the pre- and postischemic damaged motor cortex of the mouse [104]. This work proves that CNTs have a potential to deliver siRNA into the brain leading to stroke prevention and treatment in stroke victims.

The neuroprotective agents are active in preventing the oxidative stress due to blood flow restoration or reperfusion surgery [123]. This mechanism aids in the treatment of stroke. Stem cells that contain scaffolds can be transplanted into the diseased sites of the CNS and this procedure is considered as one of the strategies for treatment of stroke [124]. Positive results have been obtained when CNTs were used as scaffolds in neuronal cells and tissues [76, 79, 125].

Stroke causes a disruption of the structure of the brain. However, neurons are protected from injury in the presence of amine-modified SWCNTs [126]. Neurons were protected from injury and functional motor recovery was enhanced in stroke-induced rats following pretreatment with aminefunctionalized SWCNTs. Sprague-Dawley rats were pretreated with amine SWCNTs and phosphate buffered saline (PBS) in the right lateral ventricles of the brain one week prior to induction of ischemic brain injury. Damage in the brain tissue of stroke-induced rats was assessed and it was found that damage in the rats treated with amine-functionalized SWCNTs was much less as opposed to untreated rats. Hemispheric lesion area of $95 \%$ in PBS treated stroke-induced rats was decreased to $15 \%$ in amine SWCNT-treated strokeinduced rats after 90 days of middle cerebral artery occlusion (MCAO) [103].

In order to evaluate their motor functions, rats were placed on the rotating rod and the time taken to fall ascertained, with those administered with the SWCNTs maintaining their balance for longer. These findings suggest the beneficial role of functionalized SWCNTs in improving functioning of neurons following stroke. It was demonstrated in another study that CNTs enhanced recovery of motor functions in stroke when they were impregnated with neural progenitor cells and implanted in the brain. The use of CNTs for the improvement of stem cell differentiation for the treatment of stroke was first demonstrated by Moon and colleagues [113].

The findings demonstrate the instrumental role of the siRNA functionalized CNTs in the improvement of neuronal functions after stroke.

\section{Carbon Nanotubes in Stimuli-Responsiveness in Biomedical Applications}

As highlighted, CNTs have the potential to be applied in biosciences as nanodevices (e.g., bioprobes or biosensors). CNTs assist in enabling nanodevices to respond to stimuli such as enzymes, glutathione, proteins, ions, $\mathrm{pH}$, and temperature. However, they do not have capabilities to innately respond to stimuli. In order for the CNTs to be applied in nanodevices, they need to be first functionalized using various organic and organometallic structures, linear and hyperbranched polymers, and biological and bioactive species such as proteins. Functionalization of CNTs increases their solubility in aqueous media, biocompatibilities, and sensitivities to surrounding conditions which include temperature, ionic strength, $\mathrm{pH}$, and biomolecules [127]. The functionalized CNTs have the ability to respond to environmental stimuli and as a result they have potential to be applied in the diagnosis and treatment of stroke.

Wang and Chen suspended SWCNTs in poly(N-isopropylacrylamide) and poly-L-lysine solutions for temperatureand $\mathrm{pH}$-responsiveness, respectively [128]. The suspensions were sonicated and centrifuged, and the supernatants were finally dialyzed and assessed for their stimuli-responsiveness. For temperature-responsiveness, when poly(N-isopropylacrylamide)-CNTs were heated at $40^{\circ} \mathrm{C}$, the solution became turbid and subsequently clear again when it was cooled down. For pH-responsiveness, the poly-L-lysine-CNT solution was exposed to various $\mathrm{pH}$ ranges (acidic, neutral, and alkaline). The solution became turbid at high $\mathrm{pH}$ (9.7) and turbidity decreased with a drop in $\mathrm{pH}$. The solution became clear at neutral and low $\mathrm{pH}$ values [128]. In summary, the change in temperature and $\mathrm{pH}$ enables reversibility of dispersion and aggregation states of SWCNTs in poly(N-isopropylacrylamide) and poly-L-lysine solutions. Polymer-SWCNTs responsive to environmental stimuli have the capacity to be utilized in biosensing and drug and gene delivery, and these may revolutionize diagnosis and treatment of ischemic stroke. 
Töröcsik and colleagues [129] developed a controlled release system containing CNTs responsive to environmental stimuli. Fluorescein was encapsulated into MWCNTs by opening the CNTs at the tips through oxidation and filling their cavities with fluorescein. The CNTs were then sealed with silica nanospheres. The release of fluorescein from the CNTs was done in a controlled fashion by cleaving the chemical bond between CNTs and silica nanospheres by various external stimuli (e.g., addition of disulphide reducing agents or thermal treatment) [130].

This system has a potential application in the diagnosis including treatment of ischemic stroke and other neurological pathologies.

\section{Carbon Nanotubes Currently on the Market and Limitations to Clinical Application and Commercialization}

There is a broad spectrum of applications of CNTs in electronics, energy storage, materials science and engineering, diagnostics, and biomedicine. The controversy of CNTs with regard to their toxicity has slowed down the efforts for further innovation in their implementation especially in the clinical setting and hinders the CNT progress from the lab to clinical trials [36]. There is a lack of long-term toxicity research on CNTs as a higher proportion of toxicity studies conducted were for a short duration. As highlighted, toxicity also depends on CNT functionalization and physicochemical properties of CNTs.

As highlighted, CNT nanoscaffolds contribute significantly to stem cell therapy as they have the ability to regulate stem cell growth and differentiation in a controlled manner. CNTs do have their drawbacks despite their fascinating benefits. They are hydrophobic and heterogeneous in size leading to nonreproducible results. Based on this, there is a need for the design of a system for producing CNTs of homogenous size for future applications of therapeutics consisting of CNTs in clinical trials [121]. The inability of CNTs to attain adequate and controllable drug release has also contributed to the slow pace of CNT use in clinical trials [131]. CNT-drug complexes are less active as compared to free drugs as a result of a generally uncontrollable and low rate of drug release from the complexes. It is also a major challenge to ensure the uniformity and consistency of CNTdrug complexes due to heterogeneity of CNTs. There are also a number of challenges in drug release which include development costs. Very expensive equipment and materials for achieving controlled drug release may be needed [132]. The release of the drug might be changed by food ingestion and gastric transit time. Orally administered systems should not be chewed as this may affect controlled release leading to loss of slow release [132].

Thus, despite innumerable promising results of CNTs in biomedicine, there are challenges which need to be dealt with prior to CNT integration into biomedical devices and technology. The advances that are required to witness CNT application in the clinical setting and commercialization include (i) improvement of the sensitivity of the CNT-based biosensors,

(ii) efficient loading and unloading of drugs to and from the CNTs,

(iii) reduction in nonspecific bonding of $\mathrm{CNT}$ to the site of interest,

(iv) further investigation of long-term nanotoxicity of CNTs employing a variety of animal models and various doses,

(v) identification of noninvasive methods for direct injection of CNT-drug complexes at diseased site,

(vi) prevention of leakage of encapsulated drugs from the CNTs,

(vii) production of homogenous CNTs to improve in vivo pharmacokinetics of CNTs,

(viii) higher doses to facilitate bioavailability of siRNA for effective gene silencing,

(ix) development of effective scaffolds from CNT hybrid to promote cell adhesion, growth, differentiation, and proliferation [70, 128].

In terms of CNT systems with biomedical applications approaching market readiness, Ensysce Biosciences developed SWCNTs conjugated siRNA for treatment of cancer. They received regulatory approval to conduct clinical trials on siRNA delivery into tumour cells. Use of CNTs for improving the imaging of colorectal cancer was approved by the US Food and Drug Administration [133].

There is a very slow rate of CNT clinical trials as a result of their toxicity controversy. Further work is required to ascertain the toxicity of the CNTs prior to implementation in clinical trials.

\section{Future Potential Applications of CNTs}

Intensive research on CNTs is being undertaken in the areas of targeted drug delivery, nanoscaffolds for tissue engineering, biomedical imaging and detection for treatment of diseases, and health monitoring. CNTs have potential in the design of theranostic systems for simultaneous targeted drug delivery and detection of disease due to their physicochemical properties [134]. In future, CNTs could be used as theranostic tools for simultaneous detection and treatment of ischemic stroke for a potential reduction in adverse side effects compared to conventional stroke treatments as demonstrated from previous studies [121].

Ultrasensitive markers could be coupled to CNTs to enhance their targeting properties. This approach could be implemented in future to differentiate between the diseased and healthy tissues [135]. MWCNTs have a potential for use as nanodevices to enhance therapeutic protocols for transplantation and homing of stem cells for in vivo treatment of neurological disorders [136].

Since CNTs can act as vectors for siRNA in vivo, they have the future potential for use in silencing the genes of the caspase- 3 enzyme resulting in a reduction in neuronal 
damage and promotion of neuroprotection [137]. In future, robust and reproducible biosensors employing CNTs that can be used at the point of care could be fabricated and these biosensors would be of low cost and could be disposed of after use or be recycled. They could be user-friendly for use by even the layman for detection of biomarkers in neurological diseases including stroke [84]. The small size, high surface area, specificity, and multifunctionality of CNTs are expected to play a pivotal role in the revolutionary development of brain-specific diagnostic, imaging and drug delivery tools. These nanoengineered systems have the potential to contribute significantly to novel approaches for better understanding of the diagnosis and treatment of acute and chronic neurological CNS disorders [8]. The use of CNTs in drug delivery, detection, and tissue engineering has shown the potential to revolutionize medicine $[133,138]$.

\section{Conclusions}

In this review we discussed the promising future of CNT incorporation into neuromedicine with a special focus on their roles in imaging, drug delivery, biosensing, and neuroengineering with a specific focus on ischemic stroke. A broad perspective on CNT toxicity, functionalization, stimuli-responsiveness, and CNTs in neural tissue repair was provided. Future applications of CNTs have been discussed, evaluating their extent of advancement in the detection and treatment of neurological and ischemic disorders. There are certain challenges ahead such as toxicity, heterogeneity, and dispersibility that must be dealt with prior to successful integration of CNTs into biomedical devices and technology. Functionalization was found to play a paramount role in enhancing the potential of CNTs for application in clinical settings. Indeed application of CNT technology may revolutionize the diagnosis and treatment of ischemic stroke and other neurological disorders.

$\begin{array}{ll}\text { Abbreviations } \\ \text { CNTs: } & \text { Carbon nanotubes } \\ \text { MWCNTs: } & \text { Multiwalled carbon nanotubes } \\ \text { DDS: } & \text { Drug delivery system } \\ \text { siRNA: } & \text { Small interfering ribonucleic acid } \\ \text { PEG: } & \text { Polyethylene glycol } \\ \text { SWCNTs: } & \text { Single-walled carbon nanotubes } \\ \text { BBB: } & \text { Blood brain barrier } \\ \text { CVD: } & \text { Chemical vapour deposition } \\ \text { f-MWCNTs: } & \text { Functionalized MWCNTs } \\ \text { PEI: } & \text { Polyethylenediamine } \\ \text { CNS: } & \text { Central nervous system } \\ \text { MCAO: } & \text { Middle cerebral artery occlusion } \\ \text { hMSC: } & \text { Human mesenchymal stem cells } \\ \text { FITC: } & \text { Fluorescein isothiocyanate } \\ \text { PC12: } & \text { Pheochromocytoma cell line } \\ \text { TLR: } & \text { Toll-like receptor } \\ \text { CpG: } & \text { Cytosine phosphodiester guanine } \\ \text { MEAs: } & \text { Microelectrode assays } \\ \text { CNTYEs: } & \text { CNT yarn microelectrodes } \\ \text { PBS: } & \text { Phosphate buffered saline }\end{array}$

$\begin{array}{ll}\text { DTPA- }{ }^{111} \text { In: } & \begin{array}{l}\text { Diethylenetriaminepentaacetic } \\ \text { acid-radioactive indium }\end{array} \\ \text { ssDNA: } & \text { Single-strand deoxyribonucleic acid } \\ \text { ROS: } & \text { Reactive oxygen species } \\ \text { NF- } \kappa \text { B: } & \text { Nuclear factor kappa B } \\ \text { GSH: } & \text { Glutathione } \\ \text { PPy: } & \text { Polypyrrole } \\ \text { RES: } & \text { Reticuloendothelial system } \\ \text { PPF: } & \text { Poly(propylene fumarate) } \\ \text { CNT-FET: } & \text { CNT field effect transistors. }\end{array}$

\section{Competing Interests}

The authors declare no conflict of interests with regard to the publication of this paper.

\section{Acknowledgments}

This work was funded by the National Research Foundation (NRF) of South Africa.

\section{References}

[1] F. Re, M. Gregori, and M. Masserini, "Nanotechnology for neurodegenerative disorders," Nanomedicine: Nanotechnology, Biology, and Medicine, vol. 8, no. 1, pp. S51-S58, 2012.

[2] G. Modi, V. Pillay, and Y. E. Choonara, "Advances in the treatment of neurodegenerative disorders employing nanotechnology," Annals of the New York Academy of Sciences, vol. 1184, pp. 154-172, 2010.

[3] J. L. Gilmore, X. Yi, L. Quan, and A. V. Kabanov, "Novel nanomaterials for clinical neuroscience," Journal of NeuroImmune Pharmacology, vol. 3, no. 2, pp. 83-94, 2008.

[4] J. Folch, D. Petrov, M. Ettcheto et al., "Current research therapeutic strategies for Alzheimer's disease treatment," Neural Plasticity, vol. 2016, Article ID 8501693, 15 pages, 2016.

[5] G. Modi, V. Pillay, Y. E. Choonara, V. M. K. Ndesendo, L. C. du Toit, and D. Naidoo, "Nanotechnological applications for the treatment of neurodegenerative disorders," Progress in Neurobiology, vol. 88, no. 4, pp. 272-285, 2009.

[6] N. Singh, V. Pillay, and Y. E. Choonara, "Advances in the treatment of Parkinson's disease," Progress in Neurobiology, vol. 81, no. 1, pp. 29-44, 2007.

[7] A. K. Kakkar and N. Dahiya, "Management of Parkinson's disease: current and future pharmacotherapy," European Journal of Pharmacology, vol. 750, pp. 74-81, 2015.

[8] S. B. Nair, A. Dileep, and G. K. Rajanikant, "Nanotechnology based diagnostic and therapeutic strategies for neuroscience with special emphasis on ischemic stroke," Current Medicinal Chemistry, vol. 19, no. 5, pp. 744-756, 2012.

[9] S. Kyle and S. Saha, "Nanotechnology for the detection and therapy of stroke," Advanced Healthcare Materials, vol. 3, no. 11, pp. 1703-1720, 2014.

[10] A. W. Grossman and J. P. Broderick, "Advances and challenges in treatment and prevention of ischemic stroke," Annals of Neurology, vol. 74, no. 3, pp. 363-372, 2013.

[11] R. J. Turner and R. Vink, "Combined tissue plasminogen activator and an NK1 tachykinin receptor antagonist: an effective treatment for reperfusion injury following acute ischemic stroke in rats," Neuroscience, vol. 220, pp. 1-10, 2012. 
[12] L. Zhang and T. J. Webster, "Nanotechnology and nanomaterials: promises for improved tissue regeneration," Nano Today, vol. 4, no. 1, pp. 66-80, 2009.

[13] A. Nunes, K. T. Al-Jamal, and K. Kostarelos, "Therapeutics, imaging and toxicity of nanomaterials in the central nervous system," Journal of Controlled Release, vol. 161, no. 2, pp. 290306, 2012.

[14] M. Prato, K. Kostarelos, and A. Bianco, "Functionalized carbon nanotubes in drug," Accounts of Chemical Research, vol. 41, pp. 60-68, 2007.

[15] S.-R. Ji, C. Liu, B. Zhang et al., "Carbon nanotubes in cancer diagnosis and therapy," Biochimica et Biophysica Acta-Reviews on Cancer, vol. 1806, no. 1, pp. 29-35, 2010.

[16] S. Ciccone, M. Cappella, and C. Borgna-Pignatti, "Ischemic stroke in infants and children: practical management in emergency," Stroke Research and Treatment, vol. 2011, Article ID 736965, 9 pages, 2011.

[17] R.-L. Chen, J. S. Balami, M. M. Esiri, L.-K. Chen, and A. M. Buchan, "Ischemic stroke in the elderly: an overview of evidence," Nature Reviews Neurology, vol. 6, no. 5, pp. 256-265, 2010.

[18] M. Beg, K. Ahmad, and P. Renjen, "Epidemiological study of incidence and risk factors of Ischemic stroke subtypes according to Trial of ORG 10172 in acute stroke treatment criteria: a 3 years, hospital-based study," International Journal of Medicine and Public Health, vol. 5, no. 1, pp. 50-54, 2015.

[19] S. Ansari, D. J. Mcconnell, G. J. Velat et al., "Peer-review reports intracranial stents for treatment of acute ischemic stroke: evolution and current status," WNEU, vol. 76, no. 6, pp. S24-S34, 2011.

[20] S. Iijima, "Helical microtubules of graphitic carbon," Nature, vol. 354, no. 6348, pp. 56-58, 1991.

[21] R. Ravindra and B. Bhat, "Synthesis of aligned carbon nanotubes by floating catalyst method using ferrocene," Journal of Metals, Materials and Minerals, vol. 21, no. 2, pp. 95-99, 2011.

[22] L. Lacerda, A. Bianco, M. Prato, and K. Kostarelos, "Carbon nanotubes as nanomedicines: from toxicology to pharmacology," Advanced Drug Delivery Reviews, vol. 58, no. 14, pp. 14601470, 2006.

[23] S. Marchesan, K. Kostarelos, A. Bianco, and M. Prato, "The winding road for carbon nanotubes in nanomedicine," Materials Today, vol. 18, no. 1, pp. 12-19, 2015.

[24] R. P. Feynman, "Theres plenty of room at the bottom," Engineering and Science, vol. 23, no. 5, pp. 22-36, 1960.

[25] E. B. Malarkey and V. Parpura, "Applications of carbon nanotubes in neurobiology," Neurodegenerative Diseases, vol. 4, no. 4, pp. 292-299, 2007.

[26] A. Fabbro, S. Bosi, L. Ballerini, and M. Prato, "Carbon nanotubes: artificial nanomaterials to engineer single neurons and neuronal networks," ACS Chemical Neuroscience, vol. 3, no. 8, pp. 611-618, 2012.

[27] M. K. Gottipati, A. Verkhratsky, and V. Parpura, "Probing astroglia with carbon nanotubes: modulation of form and function," Philosophical Transactions of the Royal Society B: Biological Sciences, vol. 369, no. 1654, 2014.

[28] L. Santiago-Rodríguez, G. Sánchez-Pomales, and C. R. Cabrera, "DNA-functionalized carbon nanotubes: synthesis, self-assembly, and applications," Israel Journal of Chemistry, vol. 50, no. 3 , pp. 277-290, 2010.

[29] Y. Ando, X. Zhao, T. Sugai, and M. Kumar, "Growing carbon nanotubes," Materials Today, vol. 7, no. 9, pp. 22-29, 2004.
[30] A. Fabbro, M. Prato, and L. Ballerini, "Carbon nanotubes in neuroregeneration and repair," Advanced Drug Delivery Reviews, vol. 65, no. 15, pp. 2034-2044, 2013.

[31] Y. Lee and K. E. Geckeler, "Carbon nanotubes in the biological interphase: the relevance of noncovalence," Advanced Materials, vol. 22, no. 36, pp. 4076-4083, 2010.

[32] J. P. Ryman-Rasmussen, M. F. Cesta, A. R. Brody et al., "Inhaled carbon nanotubes reach the subpleural tissue in mice," Nature Nanotechnology, vol. 4, no. 11, pp. 747-751, 2009.

[33] C. Buzea, I. I. Pacheco, and K. Robbie, "Nanomaterials and nanoparticles: sources and toxicity, Biointerphases, vol. 2, no. 4, pp. MR17-MR71, 2007.

[34] G. M. Mutlu, G. R. S. Budinger, A. A. Green et al., "Biocompatible nanoscale dispersion of single-walled carbon nanotubes minimizes in vivo pulmonary toxicity," Nano Letters, vol. 10, no. 5, pp. 1664-1670, 2010.

[35] M. Valko, D. Leibfritz, J. Moncol, M. T. D. Cronin, M. Mazur, and J. Telser, "Free radicals and antioxidants in normal physiological functions and human disease," The International Journal of Biochemistry and Cell Biology, vol. 39, no. 1, pp. 44-84, 2007.

[36] S. Jain, S. R. Singh, and S. Pillai, "Toxicity issues related to biomedical applications of carbon nanotubes," Journal of Nanomedicine and Nanotechnology, vol. 3, no. 5, p. 140, 2012.

[37] F. A. Witzmann and N. A. Monteiro-Riviere, "Multi-walled carbon nanotube exposure alters protein expression in human keratinocytes," Nanomedicine: Nanotechnology, Biology, and Medicine, vol. 2, no. 3, pp. 158-168, 2006.

[38] K. Flavin, I. Kopf, E. Del Canto, C. Navio, C. Bittencourt, and S. Giordani, "Controlled carboxylic acid introduction: a route to highly purified oxidised single-walled carbon nanotubes," Journal of Materials Chemistry, vol. 21, no. 44, pp. 17881-17887, 2011.

[39] Y. Ni, I. Hu, E. B. Malarkey et al., "Chemically functionalized water soluble single-walled carbon nanotubes modulate neurite outgrowth," Journal of Nanoscience and Nanotechnology, vol. 5, no. 10, pp. 1707-1712, 2005.

[40] C. Gaiiiard, G. Celiot, S. Li et al., "Carbon nanotubes carrying cell-adhesion peptides do not interfere with neuronal functionality," Advanced Materials, vol. 21, no. 28, pp. 2903-2908, 2009.

[41] L. Meng, A. Jiang, R. Chen et al., "Inhibitory effects of multiwall carbon nanotubes with high iron impurity on viability and neuronal differentiation in cultured PC12 cells," Toxicology, vol. 313, no. 1, pp. 49-58, 2013.

[42] J. Wang, P. Sun, Y. Bao, J. Liu, and L. An, "Cytotoxicity of singlewalled carbon nanotubes on PC12 cells," Toxicology in Vitro, vol. 25, no. 1, pp. 242-250, 2011.

[43] J. Wang, P. Sun, Y. Bao, B. Dou, D. Song, and Y. Li, "Vitamin E renders protection to PC12 cells against oxidative damage and apoptosis induced by single-walled carbon nanotubes," Toxicology in Vitro, vol. 26, no. 1, pp. 32-41, 2012.

[44] J. Hernández-Ferrer, R. N. Pérez-Bruzón, M. J. Azanza et al., "Study of neuron survival on polypyrrole-embedded singlewalled carbon nanotube substrates for long-term growth conditions," Journal of Biomedical Materials Research A, vol. 102, no. 12, pp. 4443-4454, 2014.

[45] P. Gustavsson, M. Hedmer, and J. Rissler, "Carbon nanotubes," in Carbon Nanotubes-Exposure, Toxicology and Protective Measures in the Work Environment, pp. 1-72, 2011.

[46] A. M. Monaco and M. Giugliano, "Carbon-based smart nanomaterials in biomedicine and neuroengineering," Beilstein Journal of Nanotechnology, vol. 5, no. 1, pp. 1849-1863, 2014. 
[47] V. C. Moore, M. S. Strano, E. H. Haroz et al., "Individually suspended single-walled carbon nanotubes in various surfactants," Nano Letters, vol. 3, no. 10, pp. 1379-1382, 2003.

[48] R. Shvartzman-Cohen, Y. Levi-Kalisman, E. Nativ-Roth, and R. Yerushalmi-Rozen, "Generic approach for dispersing singlewalled carbon nanotubes: the strength of a weak interaction," Langmuir, vol. 20, no. 15, pp. 6085-6088, 2004.

[49] G. R. Dieckmann, A. B. Dalton, P. A. Johnson et al., "Controlled assembly of carbon nanotubes by designed amphiphilic peptide helices," Journal of the American Chemical Society, vol. 125, no. 7, pp. 1770-1777, 2003.

[50] M. Zheng, A. Jagota, E. D. Semke et al., "DNA-assisted dispersion and separation of carbon nanotubes," Nature Materials, vol. 2, no. 5, pp. 338-342, 2003.

[51] D. Tasis, N. Tagmatarchis, A. Bianco, and M. Prato, "Chemistry of carbon nanotubes," Chemical Reviews, vol. 106, no. 3, pp. 1105-1136, 2006.

[52] V. E. Kagan, N. V. Konduru, W. Feng et al., "Carbon nanotubes degraded by neutrophil myeloperoxidase induce less pulmonary inflammation," Nature Nanotechnology, vol. 5, no. 5, pp. 354-359, 2010.

[53] H. Ali-Boucetta, A. Nunes, R. Sainz et al., "Asbestos-like pathogenicity of long carbon nanotubes alleviated by chemical functionalization," Angewandte Chemie, vol. 52, no. 8, pp. 22742278, 2013.

[54] Z. Ji, D. Zhang, L. Li et al., "The hepatotoxicity of multi-walled carbon nanotubes in mice," Nanotechnology, vol. 20, no. 44, Article ID 445101, 2009.

[55] S. Jain, V. S. Thakare, M. Das et al., "Toxicity of multiwalled carbon nanotubes with end defects critically depends on their functionalization density," Chemical Research in Toxicology, vol. 24, no. 11, pp. 2028-2039, 2011.

[56] E. W. Keefer, B. R. Botterman, M. I. Romero, A. F. Rossi, and G. W. Gross, "Carbon nanotube coating improves neuronal recordings," Nature Nanotechnology, vol. 3, no. 7, pp. 434-439, 2008.

[57] K. T. Al-Jamal, A. Nunes, L. Methven et al., "Degree of chemical functionalization of carbon nanotubes determines tissue distribution and excretion profile," Angewandte Chemie-International Edition, vol. 51, no. 26, pp. 6389-6393, 2012.

[58] G. Cellot, E. Cilia, S. Cipollone et al., "Carbon nanotubes might improve neuronal performance by favouring electrical shortcuts," Nature Nanotechnology, vol. 4, no. 2, pp. 126-133, 2009.

[59] D. M. Webster, P. Sundaram, and M. E. Byrne, "Injectable nanomaterials for drug delivery: carriers, targeting moieties, and therapeutics," European Journal of Pharmaceutics and Biopharmaceutics, vol. 84, no. 1, pp. 1-20, 2013.

[60] M. Shein, A. Greenbaum, T. Gabay et al., "Engineered neuronal circuits shaped and interfaced with carbon nanotube microelectrode arrays," Biomedical Microdevices, vol. 11, no. 2, pp. 495501, 2009.

[61] P. He and L. Dai, "Aligned carbon nanotube-DNA electrochemical sensors," Chemical Communications, vol. 10, no. 3, pp. 348349, 2004.

[62] H. S. Sharma, D. F. Muresanu, and A. Sharma, "Novel therapeutic strategies using nanodrug delivery, stem cells and combination therapy for CNS trauma and neurodegenerative disorders," Expert Review of Neurotherapeutics, vol. 13, no. 10, pp. 10851088, 2013.

[63] J. Tan, Y. Wang, X. Yip, F. Glynn, R. K. Shepherd, and F. Caruso, "Nanoporous peptide particles for encapsulating and releasing neurotrophic factors in an animal model of neurodegeneration," Advanced Materials, vol. 24, no. 25, pp. 3362-3366, 2012.

[64] G. P. Kotchey, Y. Zhao, V. E. Kagan, and A. Star, "Peroxidasemediated biodegradation of carbon nanotubes in vitro and in vivo," Advanced Drug Delivery Reviews, vol. 65, no. 15, pp. 19211932, 2013.

[65] A. A. John, A. P. Subramanian, M. V. Vellayappan, A. Balaji, H. Mohandas, and S. K. Jaganathan, "Carbon nanotubes and graphene as emerging candidates in neuroregeneration and neurodrug delivery," International Journal of Nanomedicine, vol. 10, article A312, pp. 4267-4277, 2015.

[66] W. M. Pardridge, "Drug transport across the blood-brain barrier," Journal of Cerebral Blood Flow and Metabolism, vol. 32, no. 11, pp. 1959-1972, 2012.

[67] E. Ben-Jacob and Y. Hanein, "Carbon nanotube microelectrodes for neuronal interfacing," Journal of Materials Chemistry, vol. 18, no. 43, pp. 5181-5186, 2008.

[68] E. B. Malarkey, K. A. Fisher, E. Bekyarova, W. Liu, R. C. Haddon, and V. Parpura, "Conductive single-walled carbon nanotube substrates modulate neuronal growth," Nano Letters, vol. 9, no. 1, pp. 264-268, 2009.

[69] R. Vidu, M. Rahman, M. Mahmoudi, M. Enachescu, T. D. Poteca, and I. Opris, "Nanostructures: a platform for brain repair and augmentation," Frontiers in Systems Neuroscience, vol. 8, article 91, 2014.

[70] P. Kesharwani, V. Gajbhiye, and N. K. Jain, "A review of nanocarriers for the delivery of small interfering RNA," Biomaterials, vol. 33, no. 29, pp. 7138-7150, 2012.

[71] Y. Nho, J. Y. Kim, D. Khang, T. J. Webster, and J. E. Lee, “Adsorption of mesenchymal stem cells and cortical neural stem cells on carbon nanotube/polycarbonate urethane," Nanomedicine, vol. 5, no. 3, pp. 409-417, 2010.

[72] J. A. Kim, E. Y. Jang, T. J. Kang et al., "Regulation of morphogenesis and neural differentiation of human mesenchymal stem cells using carbon nanotube sheets," Integrative Biology, vol. 4, no. 6, pp. 587-594, 2012.

[73] S. Vardharajula, S. Z. Ali, P. M. Tiwari et al., "Functionalized carbon nanotubes: biomedical applications," International Journal of Nanomedicine, vol. 7, pp. 5361-5374, 2012.

[74] N. Tagmatarchis and M. Prato, "Functionalization of carbon nanotubes via 1,3-dipolar cycloadditions," Journal of Materials Chemistry, vol. 14, no. 4, pp. 437-439, 2004.

[75] A. Bianco, K. Kostarelos, and M. Prato, "Making carbon nanotubes biocompatible and biodegradable," Chemical Communications, vol. 47, no. 37, pp. 10182-10188, 2011.

[76] M. Bottini, N. Rosato, and N. Bottini, "PEG-modified carbon nanotubes in biomedicine: current status and challenges ahead," Biomacromolecules, vol. 12, no. 10, pp. 3381-3393, 2011.

[77] A. J. Andersen, P. P. Wibroe, and S. M. Moghimi, "Perspectives on carbon nanotube-mediated adverse immune effects," Advanced Drug Delivery Reviews, vol. 64, no. 15, pp. 1700-1705, 2012.

[78] C. Sacchetti, K. Motamedchaboki, A. Magrini et al., "Surface polyethylene glycol conformation influences the protein corona of polyethylene glycol-modified single-walled carbon nanotubes: Potential implications on biological performance," ACS Nano, vol. 7, no. 3, pp. 1974-1989, 2013.

[79] G. Cirillo, S. Hampel, R. Klingeler et al., "Antioxidant multiwalled carbon nanotubes by free radical grafting of gallic acid: new materials for biomedical applications," Journal of Pharmacy and Pharmacology, vol. 63, no. 2, pp. 179-188, 2011. 
[80] S. Shityakov, E. Salvador, G. Pastorin, and C. Förster, "Bloodbrain barrier transport studies, aggregation, and molecular dynamics simulation of multiwalled carbon nanotube functionalized with fluorescein isothiocyanate," International Journal of Nanomedicine, vol. 10, pp. 1703-1713, 2015.

[81] D. Bonifazi, C. Nacci, R. Marega et al., "Microscopic and spectroscopic characterization of paintbrush-like single-walled carbon nanotubes," Nano Letters, vol. 6, no. 7, pp. 1408-1414, 2006.

[82] D. W. H. Fam, A. I. Y. Tok, A. Palaniappan, P. Nopphawan, A. Lohani, and S. G. Mhaisalkar, "Selective sensing of hydrogen sulphide using silver nanoparticle decorated carbon nanotubes," Sensors and Actuators B: Chemical, vol. 138, no. 1, pp. 189-192, 2009.

[83] J.-K. Lin, C.-L. Lin, Y.-C. Liang, S.-Y. Lin-Shiau, and I.-M. Juan, "Survey of catechins, gallic acid, and methylxanthines in green, oolong, pu-erh, and black teas," Journal of Agricultural and Food Chemistry, vol. 46, no. 9, pp. 3635-3642, 1998.

[84] C. Yang, M. E. Denno, P. Pyakurel, and B. J. Venton, "Recent trends in carbon nanomaterial-based electrochemical sensors for biomolecules: a review," Analytica Chimica Acta, vol. 887, pp. $17-37,2015$.

[85] C. B. Jacobs, I. N. Ivanov, M. D. Nguyen, A. G. Zestos, and B. J. Venton, "High temporal resolution measurements of dopamine with carbon nanotube yarn microelectrodes," Analytical Chemistry, vol. 86, no. 12, pp. 5721-5727, 2014.

[86] S. Beg, M. Rizwan, A. M. Sheikh, M. S. Hasnain, K. Anwer, and K. Kohli, "Advancement in carbon nanotubes: basics, biomedical applications and toxicity," Journal of Pharmacy and Pharmacology, vol. 63, no. 2, pp. 141-163, 2011.

[87] S. Sotiropoulou and N. A. Chaniotakis, "Carbon nanotube array-based biosensor," Analytical and Bioanalytical Chemistry, vol. 375, no. 1, pp. 103-105, 2003.

[88] A. A. Bhirde, V. Patel, J. Gavard et al., “Targeted killing of cancer cells in vivo and in vitro with EGF-directed carbon nanotubebased drug delivery," ACS Nano, vol. 3, no. 2, pp. 307-316, 2009.

[89] T. Gabay, E. Jakobs, E. Ben-Jacob, and Y. Hanein, "Engineered self-organization of neural networks using carbon nanotube clusters," Physica A: Statistical Mechanics and its Applications, vol. 350, no. 2-4, pp. 611-621, 2005.

[90] S. Ghosh, A. K. Sood, and N. Kumar, "Carbon nanotube flow sensors," Science, vol. 299, no. 5609, pp. 1042-1044, 2003.

[91] T. Gabay, M. Ben-David, I. Kalifa et al., "Electro-chemical and biological properties of carbon nanotube based multi-electrode arrays," Nanotechnology, vol. 18, no. 3, Article ID 035201, 2007.

[92] C.-M. Lin, Y.-T. Lee, S.-R. Yeh, and W. Fang, "Flexible carbon nanotubes electrode for neural recording," Biosensors and Bioelectronics, vol. 24, no. 9, pp. 2791-2797, 2009.

[93] G. Bardi, A. Nunes, L. Gherardini et al., "Functionalized carbon nanotubes in the brain: cellular internalization and neuroinflammatory responses," PLoS ONE, vol. 8, no. 11, article e80964, 2013.

[94] N. M. Iverson, P. W. Barone, M. Shandell et al., "In vivo biosensing via tissue-localizable near-infrared-fluorescent singlewalled carbon nanotubes," Nature Nanotechnology, vol. 8, no. 11, pp. 873-880, 2013.

[95] H. Kafa, J. T.-W. Wang, N. Rubio et al., "The interaction of carbon nanotubes with an in vitro blood-brain barrier model and mouse brain in vivo," Biomaterials, vol. 53, pp. 437-452, 2015.
[96] K. Kostarelos, A. Bianco, and M. Prato, "Promises, facts and challenges for carbon nanotubes in imaging and therapeutics," Nature Nanotechnology, vol. 4, no. 10, pp. 627-633, 2009.

[97] A. Nunes, K. Al-Jamal, T. Nakajima, M. Hariz, and K. Kostarelos, "Application of carbon nanotubes in neurology: clinical perspectives and toxicological risks," Archives of Toxicology, vol. 86, no. 7, pp. 1009-1020, 2012.

[98] D. A. Heller, E. S. Jeng, T.-K. Yeung et al., "Optical detection of DNA conformational polymorphism on single-walled carbon nanotubes," Science, vol. 311, no. 5760, pp. 508-511, 2006.

[99] D. A. Heller, S. Baik, T. E. Eurell, and M. S. Strano, "Singlewalled carbon nanotube spectroscopy in live cells: towards long-term labels and optical sensors," Advanced Materials, vol. 17, no. 23, pp. 2793-2799, 2005.

[100] G. Hong, S. Diao, J. Chang et al., "Through-skull fluorescence imaging of the brain in a new near-infrared window," Nature Photonics, vol. 8, no. 9, pp. 723-730, 2014.

[101] D. Zhao, D. Alizadeh, L. Zhang et al., "Carbon nanotubes enhance CpG uptake and potentiate antiglioma immunity," Clinical Cancer Research, vol. 17, no. 4, pp. 771-782, 2011.

[102] Z. Yang, Y. Zhang, Y. Yang et al., "Pharmacological and toxicological target organelles and safe use of single-walled carbon nanotubes as drug carriers in treating Alzheimer disease," Nanomedicine: Nanotechnology, Biology, and Medicine, vol. 6, no. 3, pp. 427-441, 2010.

[103] H. J. Lee, J. Park, O. J. Yoon et al., "Amine-modified singlewalled carbon nanotubes protect neurons from injury in a rat stroke model," Nature Nanotechnology, vol. 6, no. 2, pp. 121-125, 2011.

[104] K. T. Al-Jamal, L. Gherardini, G. Bardi et al., "Functional motor recovery from brain ischemic insult by carbon nanotube-mediated siRNA silencing," Proceedings of the National Academy of Sciences of the United States of America, vol. 108, no. 27, pp. 10952-10957, 2011.

[105] H. Bjartmarz and S. Rehncrona, "Comparison of accuracy and precision between frame-based and frameless stereotactic navigation for deep brain stimulation electrode implantation," Stereotactic and Functional Neurosurgery, vol. 85, no. 5, pp. 235242, 2007.

[106] S. D. Skaper, "The biology of neurotrophins, signalling pathways, and functional peptide mimetics of neurotrophins and their receptors," CNS and Neurological Disorders-Drug Targets, vol. 7, no. 1, pp. 46-62, 2008.

[107] V. Kuzmenko, T. Kalogeropoulos, J. Thunberg et al., "Enhanced growth of neural networks on conductive cellulose-derived nanofibrous scaffolds," Materials Science and Engineering C, vol. 58, pp. 14-23, 2016.

[108] S. L. Edwards, J. A. Werkmeister, and J. A. M. Ramshaw, "Carbon nanotubes in scaffolds for tissue engineering," Expert Review of Medical Devices, vol. 6, no. 5, pp. 499-505, 2009.

[109] C. Fisher, A. E. Rider, Z. Jun Han, S. Kumar, I. Levchenko, and K. Ostrikov, "Applications and nanotoxicity of carbon nanotubes and graphene in biomedicine," Journal of Nanomaterials, vol. 2012, Article ID 315185, 19 pages, 2012.

[110] K. K. Bokara, J. Y. Kim, Y. I. Lee, K. Yun, T. J. Webster, and J. E. Lee, "Biocompatability of carbon nanotubes with stem cells to treat CNS injuries," Anatomy \& Cell Biology, vol. 46, no. 2, pp. 85-92, 2013.

[111] J. Stockwell, N. Abdi, X. Lu, O. Maheshwari, and C. Taghibiglou, "Novel central nervous system drug delivery systems," Chemical Biology and Drug Design, vol. 83, no. 5, pp. 507-520, 2014. 
[112] S. A. Pathan, Z. Iqbal, S. M. A. Zaidi et al., "CNS drug delivery systems: novel approaches," Recent Patents on Drug Delivery \& Formulation, vol. 3, no. 1, pp. 71-89, 2009.

[113] S. U. Moon, J. Kim, K. K. Bokara et al., "Carbon nanotubes impregnated with subventricular zone neural progenitor cells promotes recovery from stroke," International Journal of Nanomedicine, vol. 7, pp. 2751-2765, 2012.

[114] J. T.-W. Wang and K. T. Al-Jamal, "Functionalized carbon nanotubes: revolution in brain delivery," Nanomedicine, vol. 10, no. 17, pp. 2639-2642, 2015.

[115] J. A. Roman, T. L. Niedzielko, R. C. Haddon, V. Parpura, and C. L. Floyd, "Single-walled carbon nanotubes chemically functionalized with polyethylene glycol promote tissue repair in a rat model of spinal cord injury," Journal of Neurotrauma, vol. 28, no. 11, pp. 2349-2362, 2011.

[116] P. A. Tran, L. Zhang, and T. J. Webster, "Carbon nanofibers and carbon nanotubes in regenerative medicine," Advanced Drug Delivery Reviews, vol. 61, no. 12, pp. 1097-1114, 2009.

[117] M. P. Mattson, R. C. Haddon, and A. M. Rao, "Molecular functionalization of carbon nanotubes and use as substrates for neuronal growth," Journal of Molecular Neuroscience, vol. 14, no. 3, pp. 175-182, 2000.

[118] H. Hu, Y. Ni, V. Montana, R. C. Haddon, and V. Parpura, "Chemically functionalized carbon nanotubes as substrates for neuronal growth," Nano Letters, vol. 4, no. 3, pp. 507-511, 2004.

[119] K. Matsumoto, C. Sato, Y. Naka, A. Kitazawa, R. L. D. Whitby, and N. Shimizu, "Neurite outgrowths of neurons with neurotrophin-coated carbon nanotubes," Journal of Bioscience and Bioengineering, vol. 103, no. 3, pp. 216-220, 2007.

[120] M. Giugliano, M. Prato, and L. Ballerini, "Nanomaterial/neuronal hybrid system for functional recovery of the CNS," Drug Discovery Today: Disease Models, vol. 5, no. 1, pp. 37-43, 2008.

[121] W. Shao, P. Arghya, M. Yiyong, L. Rodes, and S. Prakash, "Carbon nanotubes for use in medicine: potentials and limitations," in Syntheses and Applications of Carbon Nanotubes and Their Composites, S. Suzuki, Ed., chapter 13, pp. 285-311, InTech, Rijeka, Croatia, 2013.

[122] S. K. Bhatia, Biomaterials for Clinical Applications, Springer, Berlin, Germany, 2010.

[123] B. Elger, M. Gieseler, O. Schmuecker, I. Schumann, A. Seltz, and A. Huth, "Extended therapeutic time window after focal cerebral ischemia by non-competitive inhibition of AMPA receptors," Brain Research, vol. 1085, no. 1, pp. 189-194, 2006.

[124] K. I. Park, Y. D. Teng, and E. Y. Snyder, "The injured brain interacts reciprocally with neural stem cells supported by scaffolds to reconstitute lost tissue," Nature Biotechnology, vol. 20, no. 11, pp. 1111-1117, 2002.

[125] C. Chen, Q. Hu, J. Yan et al., "Early inhibition of HIF-1 $\alpha$ with small interfering RNA reduces ischemic-reperfused brain injury in rats," Neurobiology of Disease, vol. 33, no. 3, pp. 509$517,2009$.

[126] M. Pramanik, M. Swierczewska, D. Green, B. Sitharaman, and L. V. Wang, "Single-walled carbon nanotubes as a multimodalthermoacoustic and photoacoustic-contrast agent," Journal of Biomedical Optics, vol. 14, no. 3, Article ID 034018, 2009.

[127] C.-Y. Hong and C.-Y. Pan, "Functionalized carbon nanotubes responsive to environmental stimuli," Journal of Materials Chemistry, vol. 18, no. 16, pp. 1831-1836, 2008.

[128] D. Wang and L. Chen, "Temperature and pH-responsive singlewalled carbon nanotube dispersions," Nano Letters, vol. 7, no. 6, pp. 1480-1484, 2007.
[129] B. Töröcsik, J. M. Angelastro, and L. A. Greene, "The basic region and leucine zipper transcription factor MafK is a new nerve growth factor-responsive immediate early gene that regulates neurite outgrowth," The Journal of Neuroscience, vol. 22, no. 20, pp. 8971-8980, 2002.

[130] X. Chen, H. Chen, C. Tripisciano et al., "Carbon-nanotubebased stimuli-responsive controlled-release system," Chemistry, vol. 17, no. 16, pp. 4454-4459, 2011.

[131] B. S. Wong, S. L. Yoong, A. Jagusiak et al., "Carbon nanotubes for delivery of small molecule drugs," Advanced Drug Delivery Reviews, vol. 65, no. 15, pp. 1964-2015, 2013.

[132] A. Nokhodchi, S. Raja, P. Patel, and K. Asare-Addo, "The role of oral controlled release matrix tablets in drug delivery systems," BioImpacts, vol. 2, no. 4, pp. 175-187, 2012.

[133] D. L. Kirkpatrick, M. Weiss, A. Naumov, G. Bartholomeusz, R. B. Weisman, and O. Gliko, "Carbon nanotubes: solution for the therapeutic delivery of siRNA?" Materials, vol. 5, no. 12, pp. 278-301, 2012.

[134] S. Kushwaha, A. RastogI, A. Rai, and S. Singh, "Novel drug delivery system for anticancer drug: a review," International Journal of PharmTech Research, vol. 4, no. 2, pp. 542-553, 2012.

[135] H. He, L. A. Pham-Huy, P. Dramou, D. Xiao, P. Zuo, and C. Pham-Huy, "Carbon nanotubes: applications in pharmacy and medicine," BioMed Research International, vol. 2013, Article ID 578290, 12 pages, 2013.

[136] O. Vittorio, S. L. Duce, V. Raffa, and A. Cuschieri, Imaging and Biomedical Application of Magnetic Carbon Nanotubes, InTech, Rijeka, Croatia, 2009.

[137] K. Bates and K. Kostarelos, "Carbon nanotubes as vectors for gene therapy: past achievements, present challenges and future goals," Advanced Drug Delivery Reviews, vol. 65, no. 15, pp. 2023-2033, 2013.

[138] R. Ellis-Behnke, “Nano neurology and the four P's of central nervous system regeneration: preserve, permit, promote, plasticity," The Medical Clinics of North America, vol. 91, no. 5, pp. 937-962, 2007. 

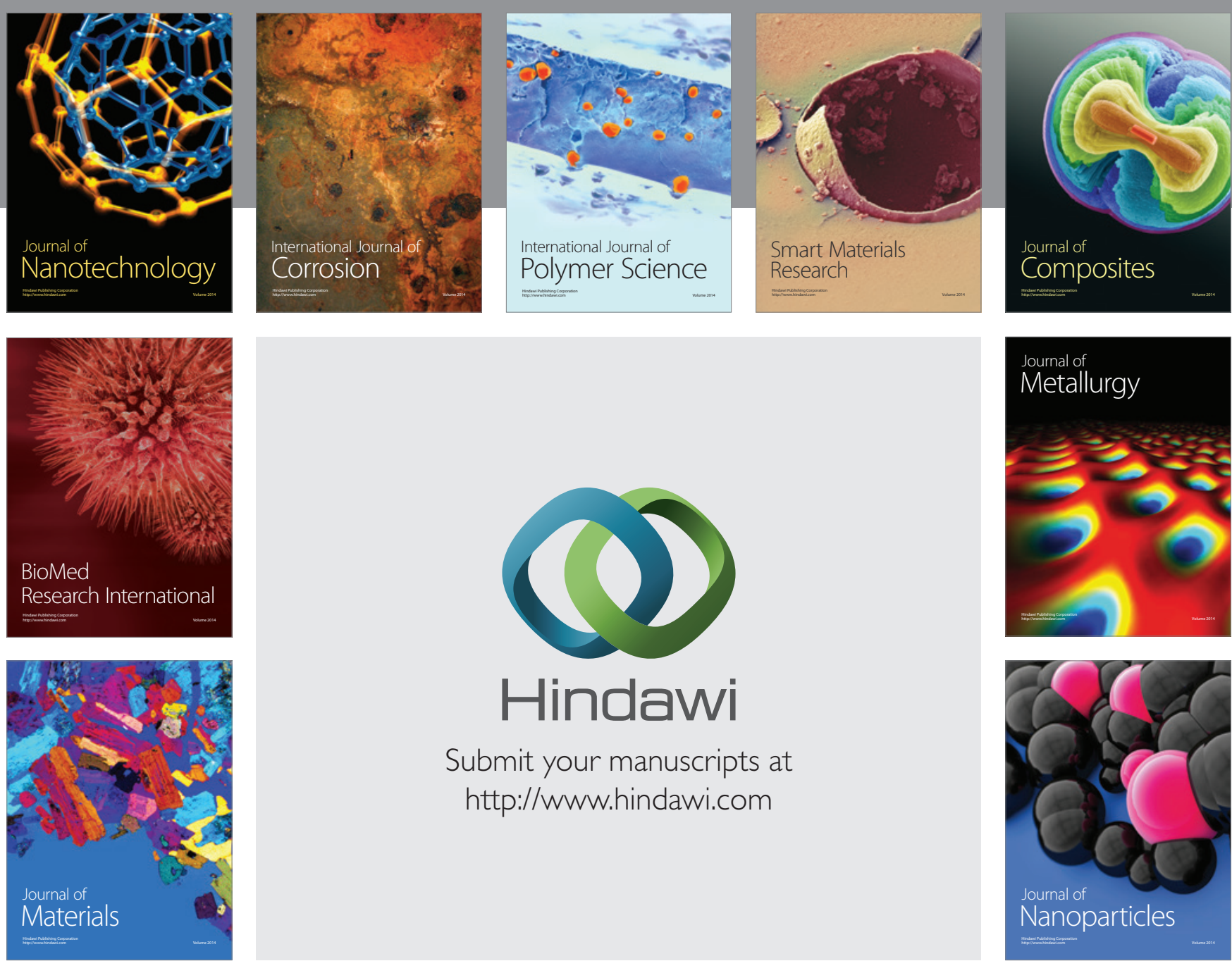

\section{Hindawi}

Submit your manuscripts at

http://www.hindawi.com

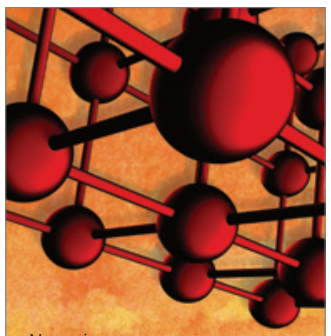

Materials Science and Engineering
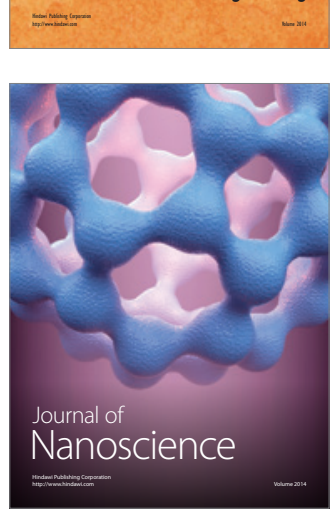
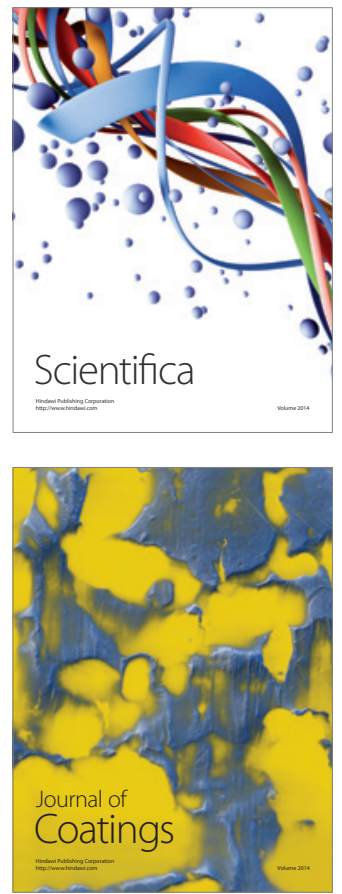
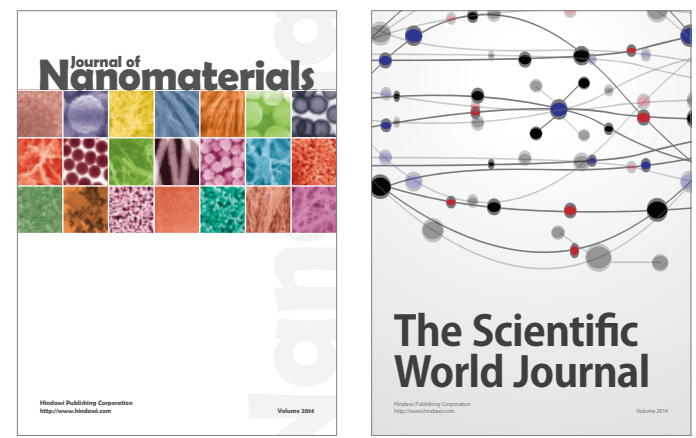

The Scientific World Journal
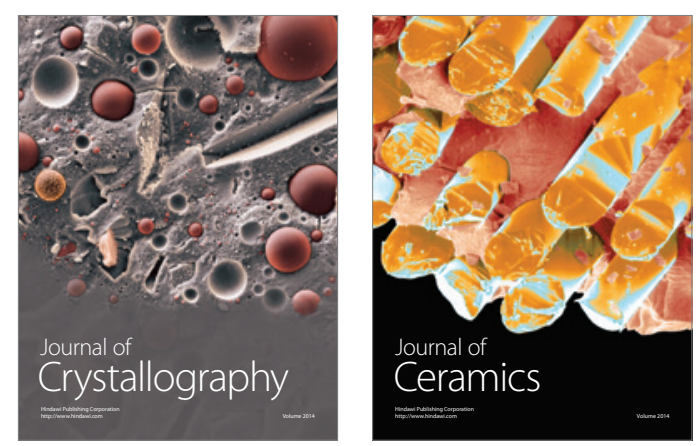
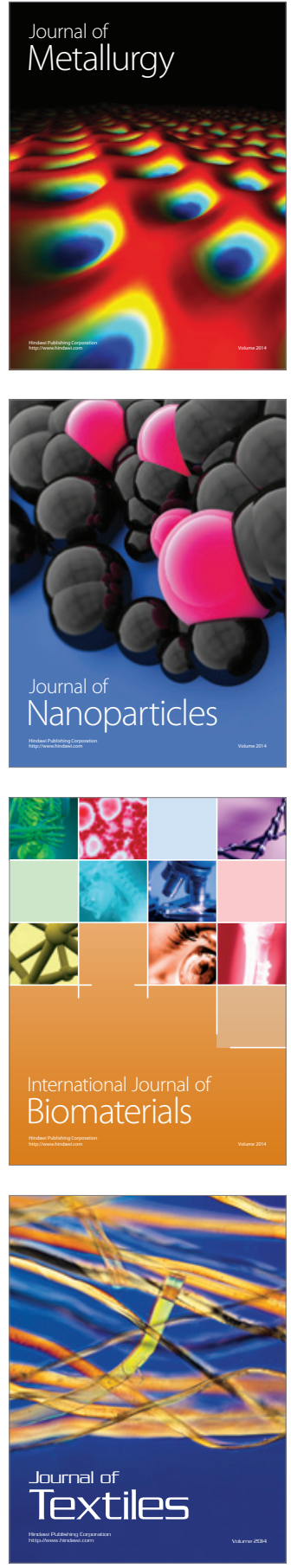